OAK

RIDGE

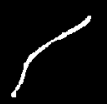

NATIONAL

LABORATORY

\title{
Use of Exiractive \\ Distillation to Produce \\ Concentrated Nitric Acid
}

UNION

cARBIDE

\author{
P. C. Campbell \\ T. P. Griffin \\ C. F. Irwin
}




\section{BSTRACT}

Concentrated nitric acid ( $>95$ wt $\%$ ) is needed for the treatment of off-gases from a fuels-reprocessing plant. The production of concentrated nitric acid by means of extractive dist,illation in the "two-pot" apparatus was studied to determine the steady-state behavior of the system. Four parameters, EDP volume (VEDP) and temperature (TEDP), acid feed rate, and solvent recycle, were independently varied. The major response factors were percent recovery (CPRR) and product purity (CCP). Stage efficiencies also provided information about the system response. Correlations developed for the response parameters are:

$$
\begin{aligned}
C P R R= & 0.02\left(V_{E D P}-800 \mathrm{cc}\right)+53.5 \\
C C P= & -0.87\left(T_{E D P}-140^{\circ} \mathrm{C}\right)+81 \\
\eta_{V, E D P}= & 9.1\left(F_{\text {feed }}-11.5 \mathrm{cc} / \mathrm{min}\right)-0.047\left(V_{E D P}-800 \mathrm{cc}\right) \\
& -2.8\left(F_{M g}\left(\mathrm{NO}_{3}\right)_{2}-50 \mathrm{cc} / \mathrm{min}\right)+390 \\
\eta_{L, E D P}= & 1.9\left(T_{E D P}-140^{\circ} \mathrm{C}\right)+79
\end{aligned}
$$

A computer simulation of the process capable of predicting steadystate coriditions was developed, but it requires further work. 


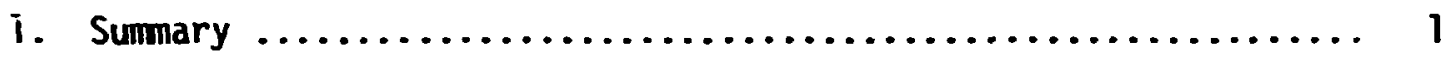

2. Introduction $\ldots \ldots \ldots \ldots \ldots \ldots \ldots \ldots \ldots \ldots \ldots \ldots \ldots \ldots \ldots \ldots \ldots$

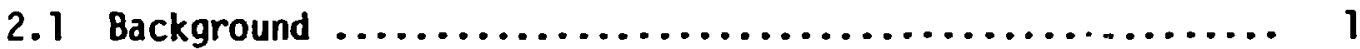

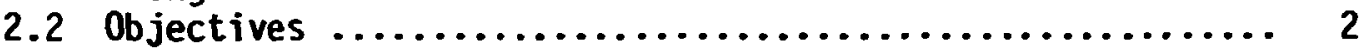

2.3 Method of Attack $\ldots \ldots \ldots \ldots \ldots \ldots \ldots \ldots \ldots \ldots \ldots \ldots \ldots \ldots \ldots$

3. Previous Work/Literature Review ..................... 5

3.1 Previous Work ............................. 5

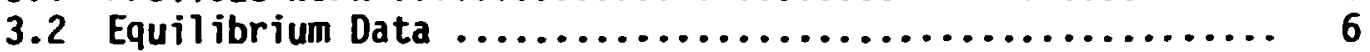

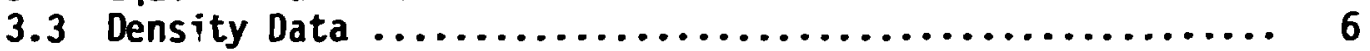

4. Experimental $\ldots \ldots \ldots \ldots \ldots \ldots \ldots \ldots \ldots \ldots \ldots \ldots \ldots \ldots \ldots \ldots$

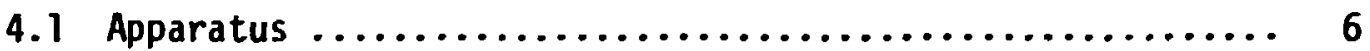

4.2 Procedure ....................................... 9

4.3 Design of Experimental Program ................... 9

4.3.1 Factors ............................... 9

4.3.2 Reproducibility ......................... 10

4.3.3 Factorial Design ...................... 14

5. Theoretical Model $\ldots \ldots \ldots \ldots \ldots \ldots \ldots \ldots \ldots \ldots \ldots \ldots \ldots \ldots \ldots$

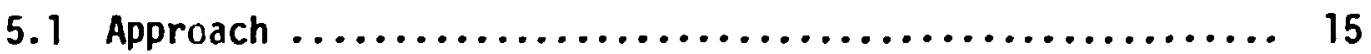

5.2 Equi? ibrium Modol $\ldots \ldots \ldots \ldots \ldots \ldots \ldots \ldots \ldots \ldots \ldots \ldots \ldots \ldots \ldots$

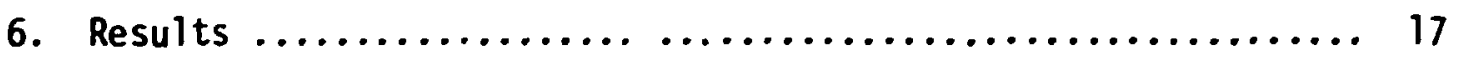

7. Analysis and Discussion of Results $\ldots \ldots \ldots \ldots \ldots \ldots \ldots \ldots \ldots$

7.1 Statistical Analysis ......................... 19

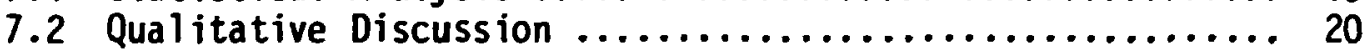

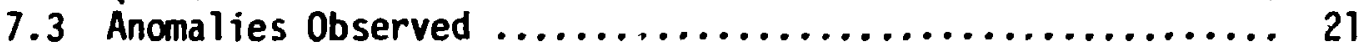

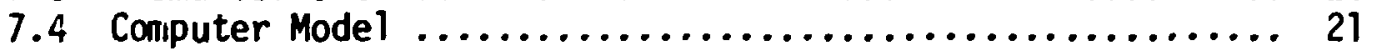

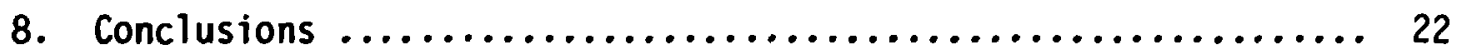

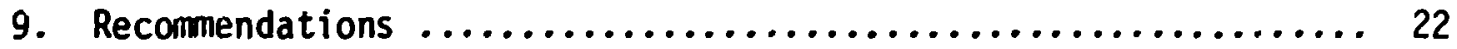

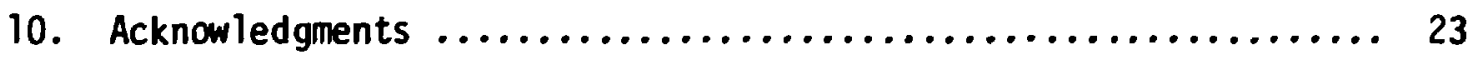

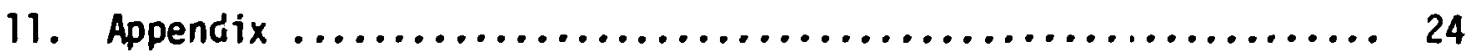

11.1 Experimental Data .......................... 24

11.2 Sample Set of Analytical Calculations for Run ACR-48 .... 28

11.3 Estimation of Experimental Error .................. 31

11.4 Calculation of Stage Efficienckes $\ldots \ldots \ldots \ldots \ldots \ldots \ldots \ldots . \ldots \ldots$

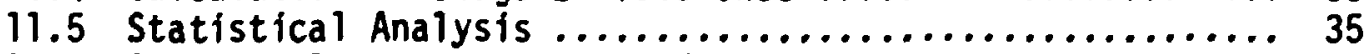

11.6 Analytical Laboratory Procedures ................ 38

11.7 Computer Model ........................... 39

11.8 Location of Data ........................... 50

11.9 Nomenclature $\ldots \ldots \ldots \ldots \ldots \ldots \ldots \ldots \ldots \ldots \ldots \ldots \ldots \ldots \ldots . \ldots \ldots$

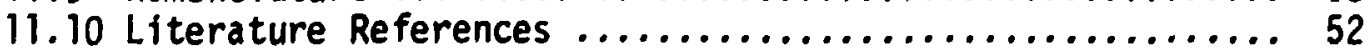




\section{SUMARY}

The Consolidated Fuel Reprocessing Program is currently developing the Iodox Process for the scrubbing of iodine com,ounds from effluent gases of the Hot Engineering Facility (HEF). The Irdor Process consists of contacting off-gases with a countercurrent st:- $-9 m$ of concentrated nitric acid. It is economically desirable to reconcentrate and then recycle the dilute aqueous nitric acid bottoms stream. Simple distillation cannot be used to dehydrate the acid because of an azeotrope at 68.5 wt \% nitric acid. However, extractive distillation with magnesium nitrate solution as a solvent can be used to produce hyjerazeotropic acid. A novel method, the "two-pot" concept for this extractive distillation was developed and studied.

The two-pot apparatus consists of an extractive distillation pot (EDP) and a solvent-recovery pot (SRP). A factorial design was used to investigate the effect of EDP volume, EDP temperature, feed acid flow rate, and solvent recycle rate on the steady-state response of the two-pot system. The response parameters studied were the concentrated product recovery ratio (CPRR), the concentration of concentrated product (CCP), and several Hansen stage efficiencies. The experimental results showed that CPRR and CCP were the most useful response factors for design and scaleup of the two-pot system. The stage efficiencies indicated that the EDP could be better studied as a mass transfer problem. Such a study would require significant modifications to the experimental apparatus. Nevertheless, the analysis of results and the development of the mathematical model were based on the assumption that the two pots were near-equilibrium contactors.

The computer model was developed to predict the steady-state behavior of the system. The two pots were simulated as equilibrium stages, which were connected for stage efficiency in a separate step.

Recommendations for further study include the investigation of additional controlled variables as well as a greater range for those already studied. It is also recommended that the EDP be studied from a mass transfer perspective. Finally, more work will be renuired before the computer simulation of the system is fully functional.

\section{INTRODUCTION}

\subsection{Background}

The Iodox Process is designed to scrub iodine compounds from effluent gases from the Hot Engineering Facflity (HEF), thereby prevent:ng the release to the atmosphere of the radioactive isotopes $\left\langle 29{ }_{I}\right.$ and $\left.{ }_{3}\right| I_{I}$, which concentrate in the thyroid gland.

Highly concentrated $\mathrm{HNO}_{3}$ contacts fuel reprocessing off-gases in a countercurrent colurin and converts the volatile iodides, such as $H I$, to nonvolatile iodic acid $\left(\mathrm{HIO}_{3}\right)$. Water is added near the top of the column 
to facilitate the absorption of nitrous oxide. The diluted nitric acid bottoms stream is evaporated to produce a solid metaiodic acid waste $\left(\mathrm{HI}_{3} \mathrm{O}_{8}\right)$ and near-azeotropic aqueous nitric acid vapor $(68.5 \mathrm{wt} \%)$. The solid is stored as a radioactive waste. Figure 1 is a schematic diagram of the system. More detail is given by Counce et al. (1).

To make the Iodox Process economically feasible and to contain the nitric acid, it is necessary to reconcentrate and recycle the nitric acid. An azeotrope at 68.5 wt $\%$ nitric acid precludes dehydration by simple distillation.

Extractive distillation techniques are used commercially for the processing of hypoazeotropic acid to hyperazeotropic concentrations $(10)$. A particularly effective solvent for this application is an aqueous silution of magnesium nitrate $\left[\mathrm{Mg}\left(\mathrm{NO}_{3}\right)_{2}\right]$, which lowers the activity of water with respect to that of nitric acid, thereby shifting the azeotrope toward pure water and ultimately toward high magnesium nitrate concentrations, causing the azeotrope to disappear compietely. The separation includes three steps: production of hyperazeotropic $\mathrm{HnO}_{3}$ vapor, rectification of the vapor to greater than $95 \mathrm{wt} \%$ acid, and reconcentration of the magnesium nitrate for recycle.

Two schemes being considered for this process are a continuous column design and the two-pot concept (i), which uses a single vessel for contacting feed $\mathrm{HHO}_{3}$ with the magnesium nitrate and another for reconcentrating the $\mathrm{Mg}\left(\mathrm{NO}_{3}\right)_{2}$ solution. The latter proposal is shown schematically in Fig. 2 . In the extractive-distillation pot (EDP) the acid is contacted at high temperature $\left(2150^{\circ} \mathrm{C}\right)$ with the solvent, immediately vaporized, and concentrated by the absorption of water into the $\mathrm{Mg}\left(\mathrm{NO}_{3}\right)_{2}$ solution as the acid vapor bubbles upward. In the solvent-recovery pot (SRP) the $\mathrm{Mg}\left(\mathrm{NO}_{3}\right)_{2}$ is reconcentrated by boiling off water and nitric acid. Two rectifying columns are then used to concentrate both $\mathrm{HNO}_{3}$ streams, one to $95 \% \mathrm{HNO}_{\dot{i}}$ and the other to remove water and recycle acid.

Possible advantages of the two-pot system include ease of control (since remote operation will be required) and a savings in material cost (less titanium and taritalum may be required). Evaluation of the alternatives will require a pilot-plant scale study. Such a unit will also facilitate the development of elements of a control scheme and the selection of structural materidls.

\subsection{Objectives}

The two major objectives were to experimentally study the behavior of the two-pot system and to us' these data in the development of a computer simulation of the :iysteri. The experimental program was keyed to investigate the effects of crifical parameters on the response variables. The goal was to rank the parameters and to develop expresstons for the response parameters as functions of the key parameters. 


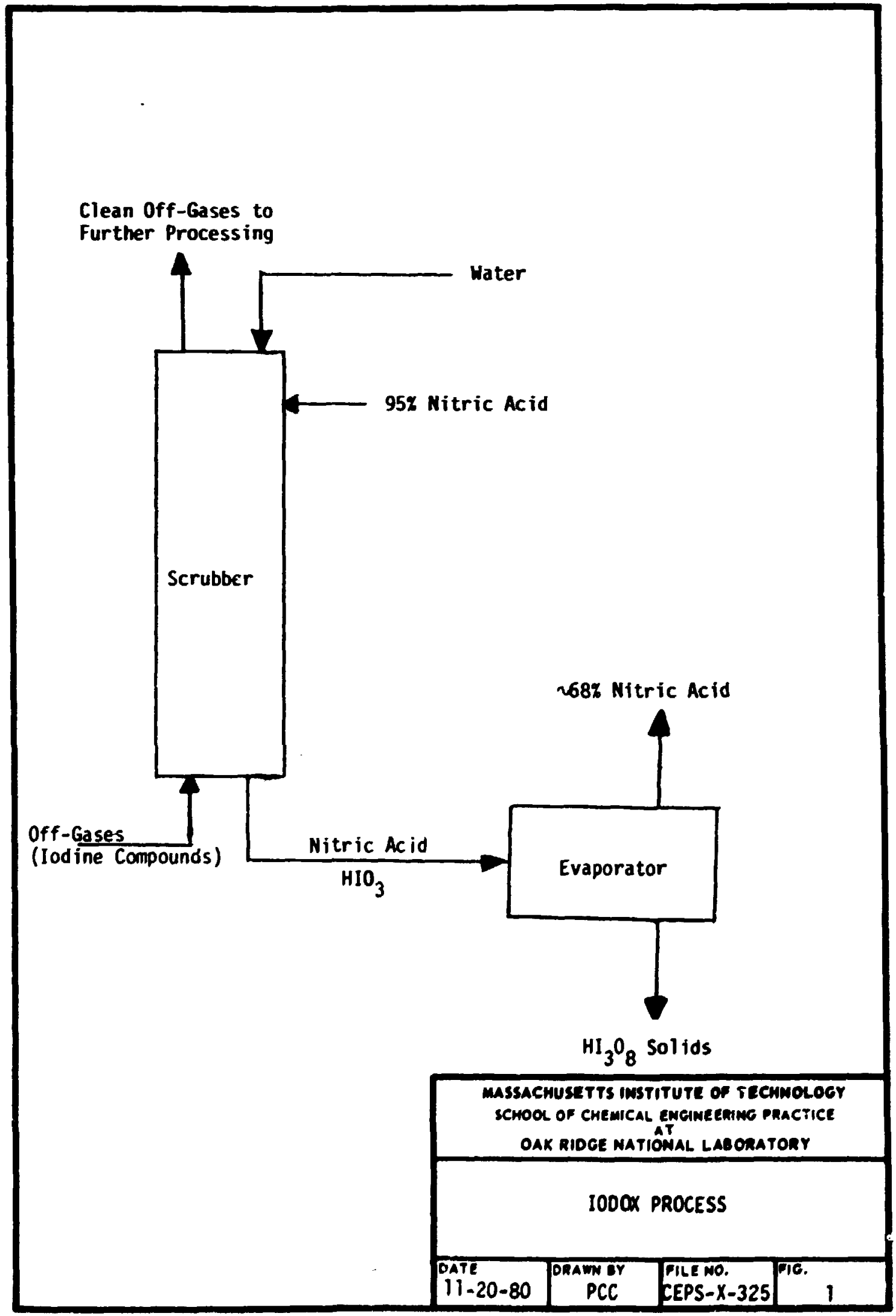




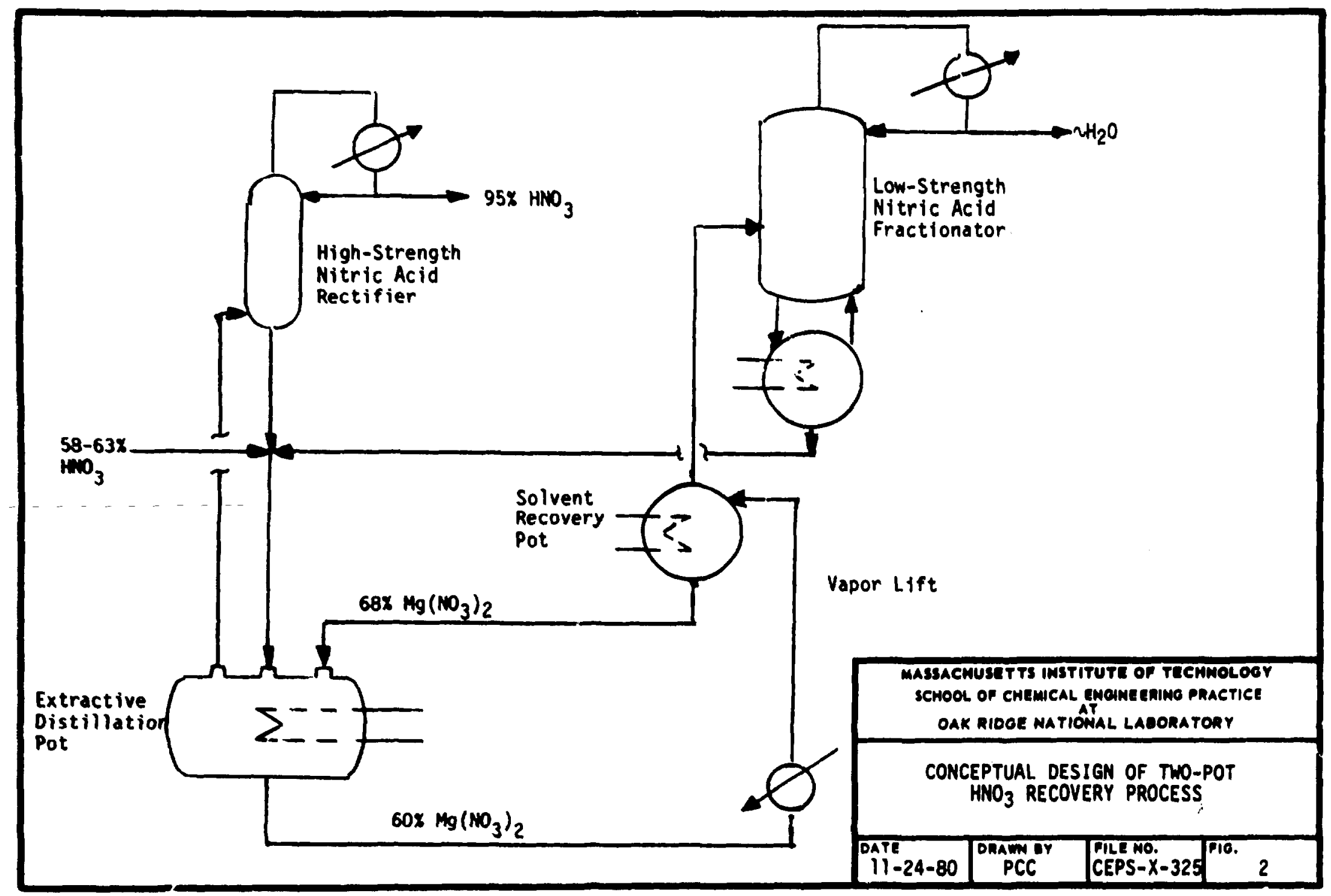


The objective of the mathematical modeling was to develop a method for predicting the steady-state performance of the two-pot system for a specified set of operating conditions. Such a model can be used to design a pilotplant-scale, two-pot system and to serve as a basis for future simulation and experimental work.

\subsection{Method of Attack}

Previous work on the two-pot system indicates that extractive separation, equilibrium data for the three-component system, and other physicalproperty data are all relevant to this study. The studies of Counce et al. (1) gave insight into suitable ranges of operating conditions and expected system behavior, and also led to the consideration of a factorial design in the current study.

The factorial experimental design, which maximized the amount of information available from a limited number of experiments, was developed. The design consisted of eight runs, each comprising a unique set of operating parameter levels. The varied parameters were: EDP temperature and volume, feed acid flow rate, and magnesium nitrate flow rate. The experimental results and equilibrium data $(2,3)$ were used to calculate stage efficiencies for both pots. FactoriaT statistical analysis was used to determine the effects of the main operating parameters and two interactions on the concentrated-product recovery ratio (CPRR), concentration of concentrated product (CCP), and the stage efficiencies.

The mathematical model was developed by treating each pot as an equilibrium flash stage, with a modification of exit stream compositions and flow rates with the stage efficiencies.

\section{PREVIOUS WORK/LITERATURE REVIEW}

\subsection{Previous Hork}

Counce et al. conducted a preliminary study on the two-pot apparatus, in which they explored the effect of EnP volume, EDP temperature, and feed-acid flow rate on the Murphree stage efficiency, the CPRR, and the $C C P$. EDP temperature and feed-acid flow rate had the strongest effects on the response facturs, while EDP volume had little or no effect. As temperature was increased, CPRR increased, CCP decreased, and Murphree stane efficiency decreased. When the acid feed rate was increased, CPRR increased, CCP stayed nearly constant, and Murpnree stage efficiency increased. The experimental error observed in this preliminary study was unusually large. Counce recommended that more studies be conducted to completely determine the effect of the controlled variables on the response parameters. 


\subsection{Equilibrium Data}

Vapor-1iquid equilibrium (VE) data for the ternary system were reported by several researchers $(2, \underline{3}, 4)$. Typically, the data were presented as constant nitric acid vapor-composition curves and constant boiling-point curves as a function of the ternary liquid composition. Empirical correlations for the isonitrate curves were developed by Cigna et al. (2). However, no correlations were found for the isotherms.

The data found for isonitrate curves are in good agreement, but the isotherms are not nearly so consistent. Figure 3 is a comparison of the three sources for a $140^{\circ} \mathrm{C}$ boiling point as a function of systen concentration. The isotherm data presented by Sloan (3) were chosen because this source is most often used by other workers in the field. The equilibrium data base used in the computer model can be easily changed to accommodate other isotherms.

\subsection{Density Data}

Density data were required for the ternary and $\mathrm{HmO}_{3}-\mathrm{H}_{2} \mathrm{O}$ systems to determine mass balances for the two-pot apparatus. Data for the binary mixtures $\mathrm{Mg}\left(\mathrm{NO}_{3}\right)_{2}-\mathrm{H}_{2} \mathrm{O}$ and $\mathrm{HNO}_{3}-\mathrm{H}_{2} \mathrm{O}$ are available. The densities of the streams containing three components were initially determined experimentally (see Sect. 4.2), and then approximated from binary data (see Appendix 11.2).

\section{EXPERIMENTAL}

\subsection{Apparatus}

The two-pot bench-scale apparatus (Fig. 4) is located in Bldg. 7601, Laboratory 2. The main units are a $1500-\mathrm{mi}$ extractive-distillation pot (EDP) and a 1500-ml solvent-recovery pot (SRP). Both are enclosed in heated cabinets and are typically operated at $150-170^{\circ} \mathrm{C}$. Feed acid flows by gravity from an elevated tank into the EOP solvent, $2 \mathrm{~cm}$ from the bottom of the pot. Because of the elevated temperature of the magnesium nitrate solution, the acid leaving the feed tube vaporizes and bubbles through the solvent, becoming more concentrated in nitric acid. The vapor product is condensed and collected for analysis. The EDP solvent is pumped continuously into the SRP, where excESS water and residual nitric acid are boiled off. The reconcentrated solvent is recycled to the EDP while the overhead dilute acid product is condensed.

The feed actd flow rate is manually controlled and observed by a rotameter, which is calfbrated for the feed acid concentration studied. 


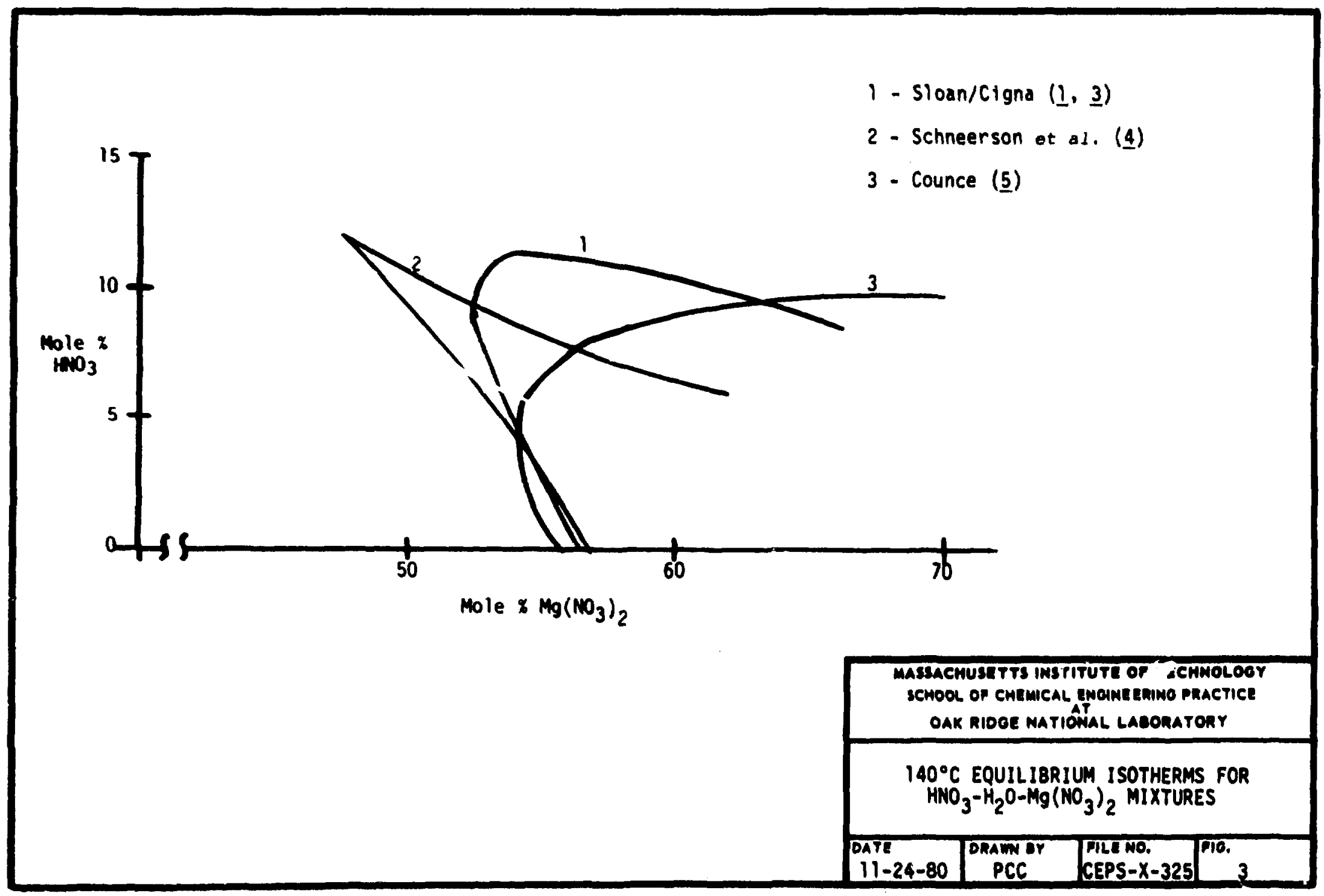


8

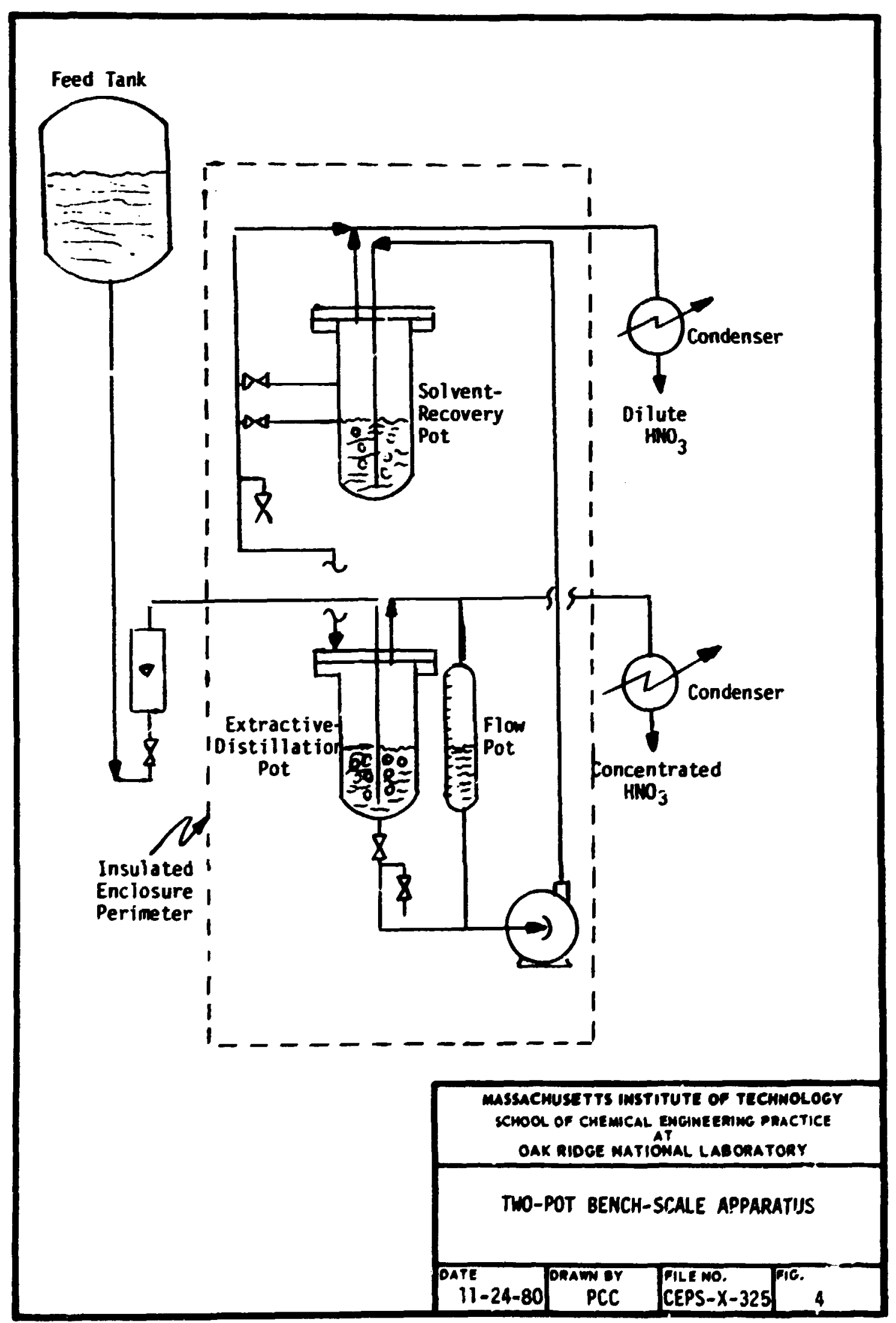


The magnesium nitrate recycle flow rate is controlled by a variable speed pump and measured with a burette (flow pnt) connected in parallel with the EDP.

Heat inputs are controlled by use of a Honeywell controller. Both pots have heating mantles; heating tapes on the recycle line between the EDP and SRP provide additional heatil.g. Temperatures throughout the system are measured with thermocouples anc monitored on a strip-chart recorder.

\subsection{Procedure}

At the start of an experiment, magnesium nitrate sc?:ition is charged to the two-pot system through a funnel at the top of the SRP. The volume of the SRP is controlled by a valve on the lower of the two-level arms attached tc this pot. The EDP volume is fixed by either draining or adding solvent to obtain the required liquid height. The feed acid and solvent recycle flow rates are then fixed at the desired levels.

The system is allowed to reach steady state at the desired operating conditions. It is usually necessary to adjust the heat inputs through the mantles and heating tapes. Flow rates and temperature are continuously monitored. Three to four hours are required to rearh steady state, because the pots have relatively long residence times (>20 min) and are very sensitive to changes in each other due to the recycle stream. When steady state is reached, the system is monitored for an additional hour to ensure that no fluctuations persist. When steady state is confirmed, final operating conditions are recorded and samples are collected from the overhead and bottoms streams of both pots and from the acid feed. The densities of the two bottoms streams can be determined by taking a sample in a pycnometer jar.

The samples are then analyzed in the analytical laboratory. The acid concentrations in all samples are determined by thermometric titration with $\mathrm{NaOH}$, while the magnesium nitrate concentrations in the bottoms samples are measured by colorimeiric titration. The analytical procedure is discussed further in Appendix 11.6. An estimate of analytical experimental error is given in Appendix 11.3. In summary, the estimated error in overall material balance is approximately $20 \%$, while stage-efficiency estimates are in the range of $15 \%$. Obviously this points cut a need for improved analytical techniques.

\subsection{Design of Experimental Program}

\subsubsection{Factors}

The factors which can be directly controlled are the EDP temperature and volume, SRP temperature and volume, acid feed concentration, and flow 
rates of the acid feed and the solvent recycle. Setting these factors in each experiment fixes the compositions of all the streams (sec Sect. 4.3.2). of these factors, only four were studied: EOP temperature and volume, acid feed flow rate, and solvent recycle flow rate.

The response variables that illustrate the effects of the controlled factors on these compositions are the concentrated product recovery ratio (CPRR), the concentration of the concentrated product (CCP), and several stage efficiencies $(n)$. C? $k$ R, defined as

$$
\text { CPRR }=\frac{g / s \text { concentrated acid product }}{g / s \text { feed acid }}
$$

is a measure of recovery, while the CCP is the purity of the primary sepaI ation product. Optimization of the two-pot system design will include maximizing CPRR while exceeding a minimum CCP.

The stage efficiency indicates the degree to which equilibrium is achieved in a given pot by corrparing the actual exit composition with an equilibrium exit composition, as shown in Fig. 5. The equilibrium exit composition may be defined in several ways, each definition corresponding to a different stage efficiency. For example, in a Murphret stage efficiency, $Y_{\text {out }}^{*}$ is defined as the vapor-phase composition that would be in equil ibrium with the actual $x_{\text {opt }}$ at constant pressure. Alternately, if $\gamma_{\text {out }}^{*}$ is defined as the vapor-phase composition resulting frol.i a constant temperature and pressure equilibrium flash of the total feed stream, then the stage efficiency is called a Hansen stage efficiency. King (ㅇ) gives a detailed discussion of the Hansen and Murphree stage efficiencies.

The Hansen stage efficiency is the more appropriate response factor for this experiment, since the EDP and SRP are operated at constant temperature and pressure. The equilibrium stream compositions, required to calculate the efficiency, are determined by a flash calculation based on a combined total liquid feed stream. One feature of a computational schene involving Hansen efficiencies is that product compositions may be directly calculated. On the other hand the Murphree efficiency will necessarily involve an iterative process. Two efficiencies are necessary to describe the behavior of each pot since there are three components; liquid and vapor nitric acid efficiencies were selected.

\subsubsection{Reproducibility}

The description rule (8) for separation processes was used to specify the problem. In this analysis all the system variables and relationships were compared to determine the number of variables that must be specified to completely and uniquely fix the system. Figure 6 is a simplified block diagram of the two-pct system and its individual units. Table 1 is a summary of the analysis. 


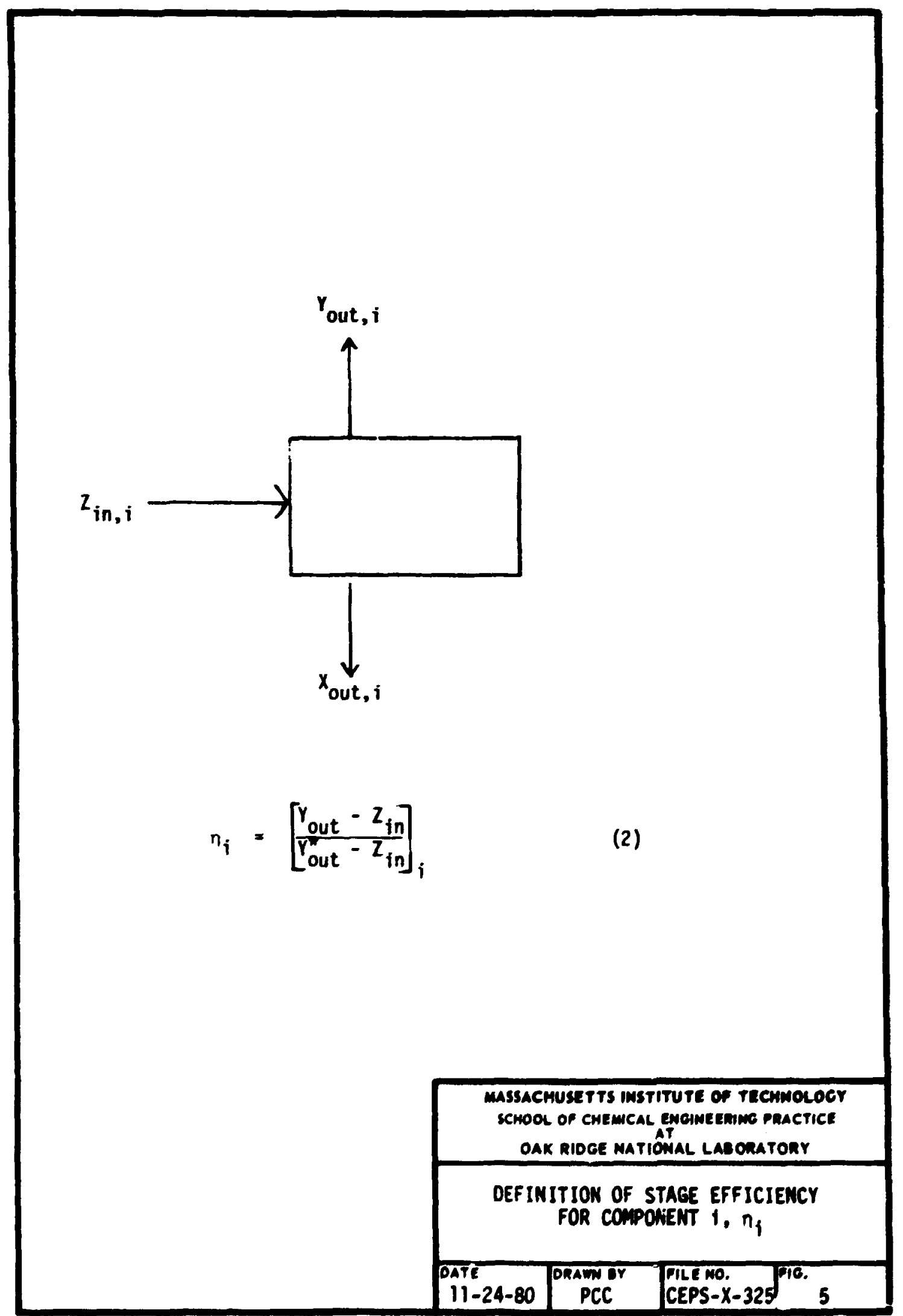




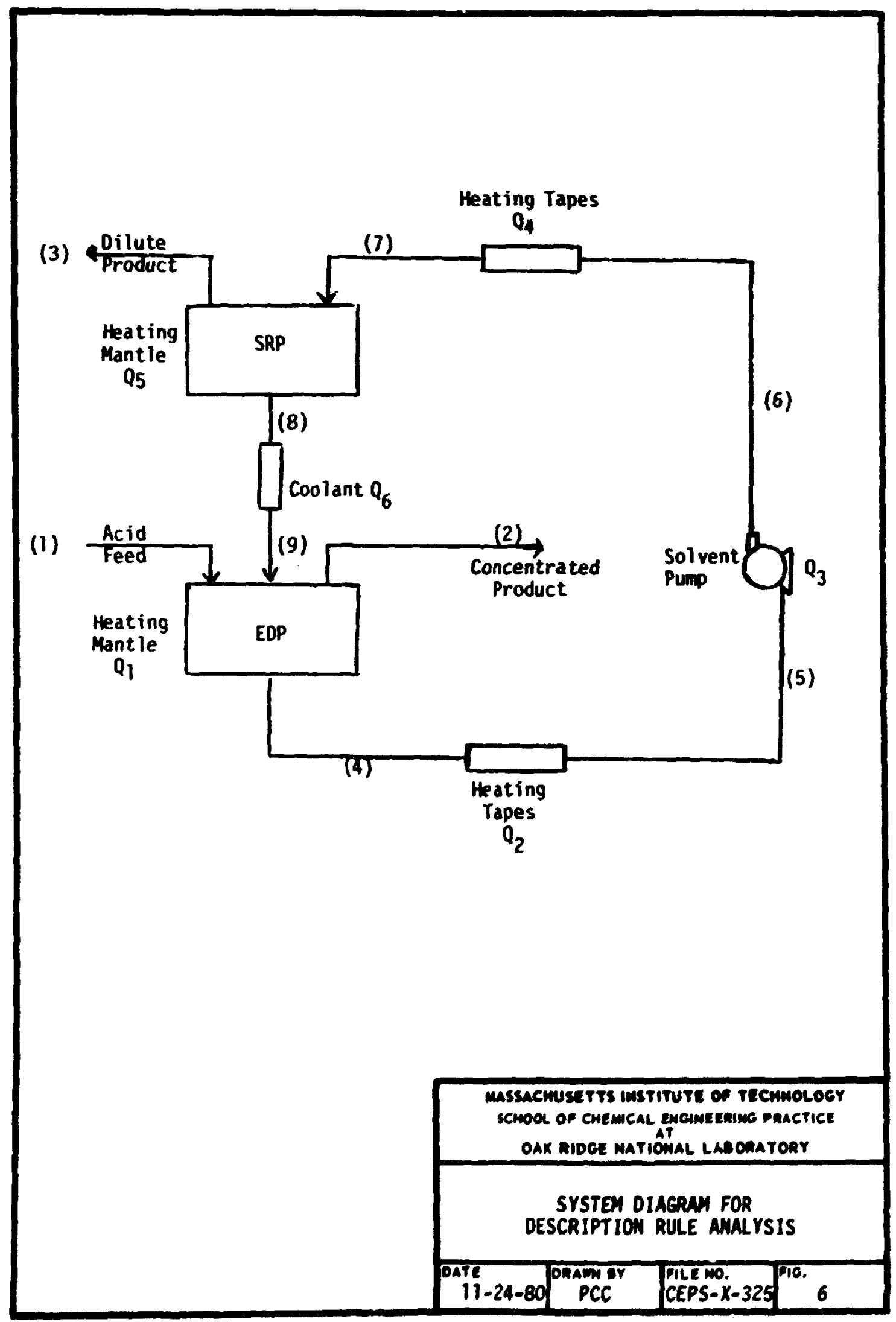


Table 1. Two-Pot Syster Specification

Variables

Composition (C)

(independent)

Flow rate (F)

Temperature (T)

Pressure (P)

Heat input (Q)

$8(2)+1=17$

Relationships

Mass Balances

Pots

$3(2)$

6

Heaters

$3(3)$

9

Pump

3

3

Vapor-Liquid Equilibrium

$Y-X$ relationships in pots 6

$T_{\text {vapor }}=T_{\text {liquid }}$ in pots 2

$P_{\text {apor }}=P_{1 \text { iquid }}$ in pots 2

Enthalpy Balances

$\frac{6}{34}$

$50-34=16$ variables that must be specified to uniquely describe the system. Specified Variables

$T$ in pots 2

$P$ in pots 2

$C, F, T$, and $P$ in acid feed 4

$F$ in Stream 6

$P$ in Stream 9

$Q$ in pots, heaters, and pump $\frac{6}{16}$ 
In brief, sixteen variables must be specified. When this is done, every experinent should be reproducible within experimental error. To determine experimental reproducibility, one experiment was a duplicate of a previous run. Good agreement was obtained (see project calculation file).

\subsubsection{Factorial Design}

A factorial design was developed to maximize the information gained from the 1 imited number of experiments. Beyund the initial practice run only eight experiments could be performed due to time restraints and several experimental setbacks. To minimize the number of wa in effects and the number of required runs, only four controllable factors (TEDP, $V_{E D P,} F_{\text {feed, }}$ and $\left.\mathrm{F}_{\mathrm{Mg}}\left(\mathrm{NO}_{3}\right)_{2}\right)$ were varied; the remaining factors (TSRP, VSRP, and $\mathrm{C}_{\text {feed }}$ ) were held constant.

Two values for each controlled factor were chosen for study (see Table 2). Several considerations irfluenced their selection (9). The values must be in a region of experimental interest and sufficiently separated so that the response parameter can exhibit a significant response. However, the two levels must lie on a planar region, as a linear correlation is intended and cannot be infinitely separated. The results of counce et al. aided in this factor-level selection.

Table 2. Factor Levels

\begin{tabular}{lccc}
\hline Factor & Units & Lower Level & Upper Level \\
\cline { 2 - 4 }$V_{\text {EDP }}$ & $\mathrm{ml}$ & 800 & 1500 \\
$T_{\text {EDP }}$ & ${ }^{\circ} \mathrm{C}$ & 140 & 155 \\
$F_{\text {acid }}$ & $\mathrm{cc} / \mathrm{min}$ & 11.5 & 16 \\
$\left.F_{\text {MgiNO}}\right)_{3}$ & $\mathrm{cc/min}$ & 50 & 65 \\
\hline
\end{tabular}

For an experimental program of eight runs and four controlled factors (two levels each), two factorial designs are recommended (9). The first is a two-level 24-1 design which consists of eight different experiments. This design yields a ranking of the main effects and no estimate of experimental error. The second design is a two-level $2^{4-2}$ program of eight runs, four runs with each duplifated once. From this design a good estimate of e:perimental error is obtained, but the main effects are confounded with each other and cannot be fsolated.

The two-level $2^{4-1}$ design was chosen because it was felt by the investigators that the ranking of main effects and important interactions, in order of importance, was of more immediate interest than an estimate of 
experimental error. Less impoitant factors can then be el iminated from future studies, which can easily include an experimental-error analysis. The complete factorial design program, including constant factors, is shown in Table 3 (see Sect. 6). A more detailed discussion of factorial design theory is given in Box, Hunter, and Hunter (9).

\section{THEORETICAL MODEL}

\subsection{Approach}

A mathematical model capable of predicting the steady-state behavior of the two-pot nitric acid dehydration apparatus was implemented on the DDP-10 system. The two-pot apparatus can be modeled as a mass-transfer problem or as an equilibrium system. In the former, the mass exchanged as the bubble rises through the magnesium nitrate systen is determined by use of mass transfer coefficients. Physically the process is complicated by the fact that the acid feed is heated as it flows down the inlet pipe (which is in contact with the contents of the pot) and probably partially vaporizes. Then the two liquid phases mix at the exit point of the pipe and further flashing ocr,urs, this time with $\mathrm{Mg}\left(\mathrm{NO}_{3}\right)_{2}$ present. Finally, the vapor phase rises through the liquid medium, providing further opportunity for mass transfer. In an equilibrium model, the vapor and liquid streams from an isothermal and isobaric flash of the combined feed are corrected for nonequilibrium with Hansen stage efficiencies. The latter model was selected because correlation of stage efficiency as a function of controlled factors can be more easily obtained from the experimental apparatus than from the mass transfer coerficients.

\subsection{Equilibrium Model}

A schematic diagram for the equilibrium model is presented in Fig. 7 . The EDP is divided into three imaginary stages: a mixing stage, an equilibrium stage, and an equilibrium modification stage. In the mixer, the acid feed and the SRP effluent are combined to form an imaginary total liquid feed stream (No. 2). This stream is then flashed, at constant temperature and pressure, to imaginary streams No. 3 (vapor) and No. 4 (1 iquid). The actual EDP effluent streams (5 and 6) are determined by adjusting the composition and flow rates of streams 3 and 4 for nonequilibrium with the Hansen stage efficiencies. The stage efficiencies are calculated from correlations expressing the effictency as a function of the controlled factors (see Sect. 6).

The SRP is modeled similarly. In this case, a mixing stage is not required as the SRP receives only one liquid feed. Two imaginary equilibrium streams ( 7 and 8 ) are determined by an equilibrium flash calculation, as in the EDP. These streams are then modified with two Hansen stage efficiencies to determine the SRP effluent streams 9 and 10. 


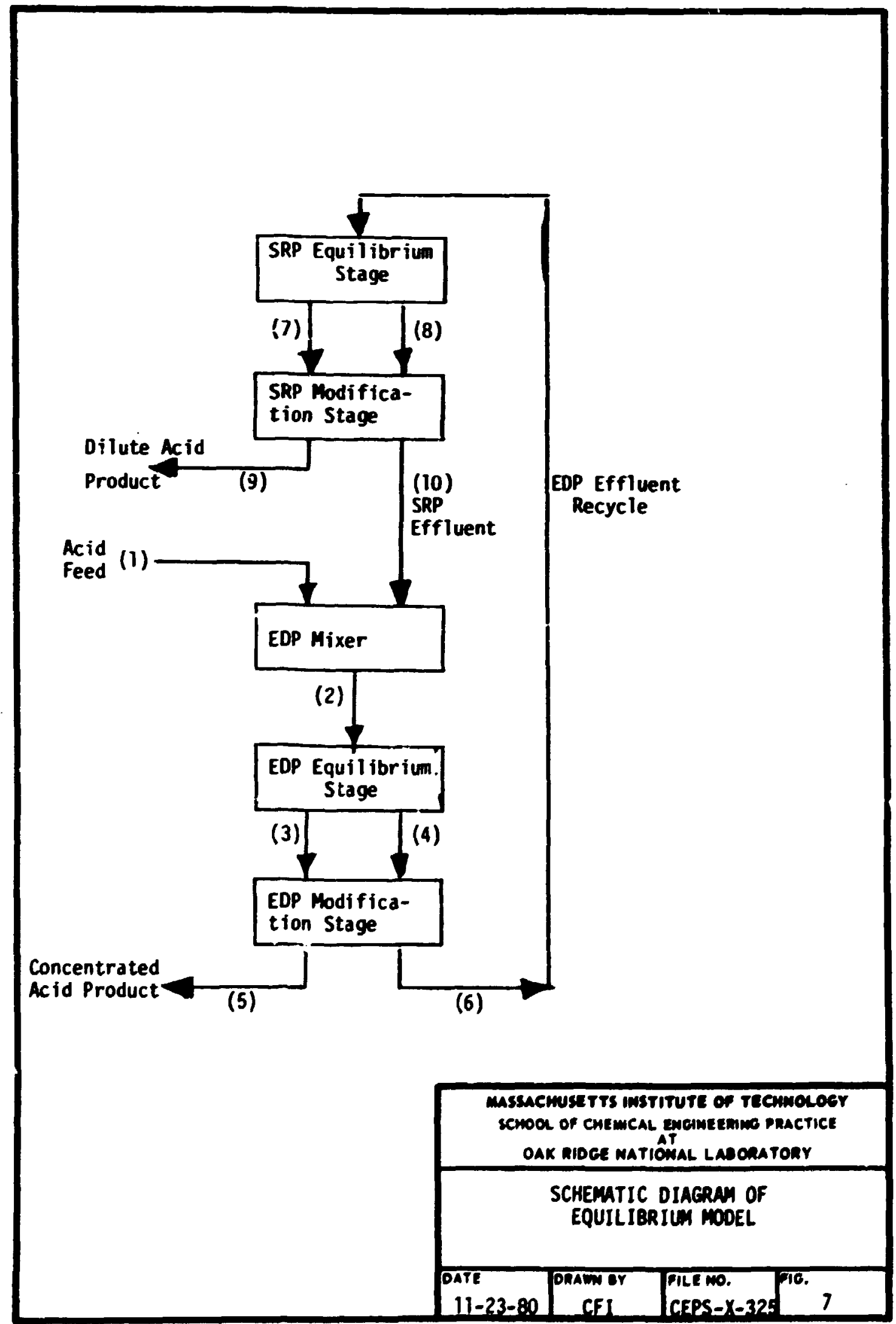




\section{RESURTS}

The experimental design and factor levels are presented in Table 3. Values to the left of the slash are upper levels; values to the right are lower levels. The raw data from each run. (stream compositions, densities, and flow rates) are presented in Appendix 11.1. The mass flow rate is the product of the volumetric flow rate and density. (Sample calculations are given in ippendix 11.2.)

Table 3. Experimental Design

\begin{tabular}{|c|c|c|c|c|c|}
\hline Run & Experiment & $\begin{array}{l}v_{\text {EDP }} \\
(\mathrm{CC})\end{array}$ & $\begin{array}{l}F_{\text {feed }} \\
\text { (cc/min) }\end{array}$ & $\begin{array}{l}\mathrm{F}_{\mathrm{Mg}}\left(\mathrm{mo}_{3}\right)_{2} \\
(\mathrm{cc} / \mathrm{min})\end{array}$ & $\begin{array}{l}T_{\text {EDP }} \\
\left({ }^{\circ} \mathrm{C}\right) \\
\end{array}$ \\
\hline 1 & ACR-42 & 1800 & $/ 11.5$ & $65 /$ & $155 /$ \\
\hline 2 & ACR-43 & $/ 800$ & $16 /$ & $/ 50$ & $155 /$ \\
\hline 3 & ACR-44 & $1500 /$ & 111.5 & $/ 50$ & $155 /$ \\
\hline 4 & ACR -45 & 1800 & $16 /$ & $65 /$ & $/ 140$ \\
\hline 5 & ACR-46 & $/ 800$ & $/ 11.5$ & $/ 50$ & 1140 \\
\hline 6 & ACR-47 & $1500 /$ & $16 /$ & $65 /$ & $155 /$ \\
\hline 7 & ACR -48 & $1500 ;$ & $16 /$ & $/ 50$ & $/ 140$ \\
\hline 8 & ACR-49 & $1500 /$ & $/ 11.5$ & $65 /$ & $/ 140$ \\
\hline
\end{tabular}

Note: Values to the left of the slash represent upper levels; values to the right of the slash represent lower levels.

Process constants: $T_{S R P}=165^{\circ} \mathrm{C}, V_{S R P}=1500 \mathrm{ml}$, and $C_{\text {feeJ acid }}=65 \%$

Calculated response factors for each run are summarized in Table 4. The CPRR is the ratic of the concentrated-product mass fiow rate $(\mathrm{g} / \mathrm{s})$ to the feed-acid mass flow rate $(\mathrm{g} / \mathrm{s})$. CCP is the concentration of the concentrated product (weight fraction $\mathrm{HMO}_{3}$ ). The efficiencies are for nitric acid in the vapor and liquid strcans from each pot; two efficiencies are required for each pot. The equilibrium exit-stream compositions were determined by a constant T,P flash calculation. This is discussed in more detail in Appendices 11.4 and 11.7 .

Table 5 shows the results of mass balance calculations used to check for error. A sample calculation is given in Appendix 11.2. The results are analyzed and discussed in the following section. 
Table 4. Response Factors

\begin{tabular}{llllcccc}
\hline RUn & & & & \multicolumn{5}{c}{ Percent Efficiencies } \\
\hline 42 & 0.756 & 0.692 & 594 & 107 & 2391 & 100 \\
43 & 0.565 & 0.676 & 322 & 113 & 2136 & $(-20)$ \\
44 & 0.756 & 0.668 & 245 & 107 & 763 & 86 \\
45 & 0.900 & 0.675 & 239 & 105 & 781 & 100 \\
46 & 0.570 & 0.779 & 281 & 94 & 366 & 106 \\
47 & 0.469 & 0.817 & 510 & 65 & 760 & 113 \\
48 & 0.311 & 0.810 & 381 & 78 & 429 & 100 \\
49 & 0.401 & 0.828 & 379 & 80 & 378 & 122 \\
\hline
\end{tabular}

Table 5. Mass Balance Check of Results

\begin{tabular}{|c|c|c|c|c|c|c|}
\hline \multirow{3}{*}{$\begin{array}{l}\text { Component } \\
\text { Run ACR- }\end{array}$} & \multicolumn{6}{|c|}{ Percent Deviations } \\
\hline & & $\mathrm{Fin}_{3}$ & & & $\mathrm{H}_{2} \mathrm{O}$ & \\
\hline & Overall & SRP & EDP & Overall & SRP & EDP \\
\hline 42 & 2.8 & -2.9 & 3.5 & 9.1 & 3.3 & -24.0 \\
\hline 43 & 22.8 & -76 & 33 & 21.4 & -3.8 & 43 \\
\hline 44 & 12.0 & -6.0 & 19.0 & 7.0 & 0.3 & 5.0 \\
\hline 45 & -3.4 & 2.2 & -3.8 & -9.3 & -3.6 & 17.7 \\
\hline 46 & -3.7 & -14.5 & 2.3 & -3.4 & -13.4 & 10.0 \\
\hline 47 & 4.6 & 27.0 & 13.6 & 1.4 & 4.4 & -44 \\
\hline 48 & 10.9 & 17.9 & 21.3 & 8.0 & 4.3 & 11.8 \\
\hline 49 & -4.3 & 5.6 & 1.0 & 1.4 & -1.1 & 9.1 \\
\hline
\end{tabular}




\section{ANALYSIS AND DISCUSSION OF RESULTS}

\subsection{Statistical Analysis}

The experimental results were analyzed by Yates' algorithm (9) to determine the main effects ( $V_{E G P}, F_{f e e d}, F_{M g}\left(M_{3}\right)_{2}$, and TEDP) and the contributions of two interactions ( $V_{E D P} \times F_{\text {feed }}$ ditd $\left.\left.{ }^{3}\right)^{2} v_{\text {EDP }} \times \mathrm{F}_{\mathrm{Mg}}\left(\mathrm{HO}_{3}\right)_{2}\right)$ for each of the four response factors. The percentage change of a resporise parameter for a change in the factor level is determined by dividing the effects by the average low value of the response variable itself (Appendix 11.5). The results of this analysis are used to rank the effects of tre factors on the response parameters (see Table 6).

Table 6. Ranking of Effects

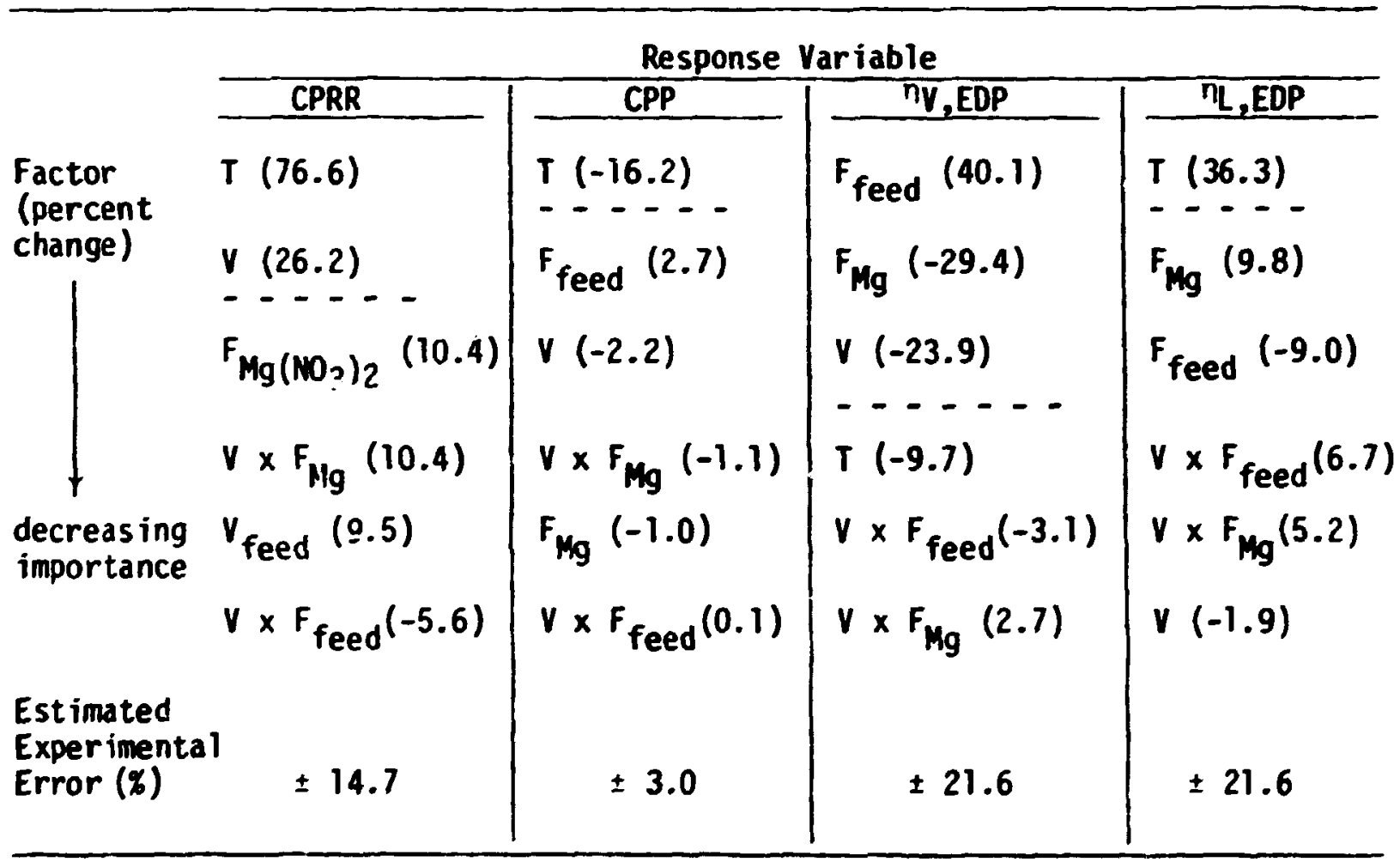

To determine which effects are insignificant, the percentage changes are compared with an estimate of minimum experimental error, which is usually determined by comparing results from duplicate experiments. Since this experimental program gave no error estimate, the "best" estimate of this error is obtained by multiplying the analytical error by 1.5 to allow for additional systematic error (Appendix 11.5). If the percentage change in a response parameter is less than the estimated error, the effect of the factor is considered insignificant. The dashed lines drawn across each 
response parameter in Table 6 separate the significant factors (above the 1 ine) from those that are insignificant.

The following relations (see Appendix 11.5) express the response parameters as functions of the remaining factors, over the range of the factor levels:

$$
\begin{aligned}
& \text { CPRR }=0.01\left(V_{E D P}-800 \mathrm{cC}\right)+1.1\left(T_{E D P}-140^{\circ} \mathrm{C}\right)+49 \\
& C C P=81-0.87\left(T_{E D P}-140^{\circ} \mathrm{C}\right) \\
& \eta_{V, E D P}=9.1\left(F_{\text {feed }}-11.5 \mathrm{cc} / \mathrm{min}\right)-0.047\left(V_{\text {EDP }}-800 \mathrm{cc}\right) \\
& -2.8\left(\mathrm{~F}_{\mathrm{Mg}\left(\mathrm{HO}_{3}\right)_{2}}-50 \mathrm{cc} / \mathrm{min}\right)+390 \\
& \eta_{\mathrm{L}, \mathrm{EDP}}=1.9\left(\mathrm{~T}-140^{\circ} \mathrm{C}\right)+79
\end{aligned}
$$

Stage-efficiency correlations for the SRP are discussed in Appendix 11.5.

The use of the factorial design for data analysis involves several assumptions. First, the levels chosen for the parameters are assumed to result in a linear model, i.e., the significant effects are linear over the range studied. Second, the effects are assumed to be additive such that additive response-factor expressions may be developed. Finally, it is assumed that all effects (second-and third-order interactions) other than those directly studied are insignificant and therefore the possibility of confounding is el iminated.

\subsection{Qualitative Discussion}

CPRR and CCP both depend strongiy on the EDP temperature. As temperature increases, CPRR (vapor product recovery) increases as more water is retained in the vapor phase. Simflarly, CCP (product purity) decreases with increasing temperature. Unexpectedly, volume, icid feed rate, and solvent recycle rate have little effect on CPRR and CCP. One explanation for this result is that the chosen values for these factors are nut in the most suitable range. Therefore, the full effects are not elicited.

The 1 iquid-phase stage efficiency for the EDP ( $\left.\eta_{L}, E D P\right)$ depends most strongly on temperature. This is expected because the' Expor-liquid equi$1 \mathrm{fbrium}$ and vapor pressures are highly temperature-dependent. The other factors did not significantly affect $\mathrm{nL}$, EDP.

The EDP vapor-phase stage efficiency ( $T$, EDP) is independent only of $T_{E D P}$. This is not expected, in light of the previous results. It is 
suspected that this efficiency is a poor choice of respcose paranter: all values of ny Enp are much greater than 100\%; and the feed composition is that of a 1 iquid, not a vapor, as should be used. This latter approximation is recessitated by the lack of a vapor feed. Nevertheless, vapor efficiencies greater than $100 \mathrm{z}$ may be possible due to the poor mixing in the EDP. Mass transfer limitations may then cause more nitric acid to remain in the vapor than predicted by the vapor-liquid equilibriu.

The system mass balances indicate that the experiment was running swoothly. In six of eight cases, all the deviations mere within the range of experimental error. The only significant discrepancies were in run ACR-43, where deviations as high as $76 \%$ were observed. This is due to operator error in determining the acid product flow rates.

Some possible sources of error were introduced in the execution of the experimental design. The acid feed concentration was specified as 65 wt $\%$ but did not remain constant throughout the experiments. Analytical results showed that this concentration ranged from 63.8 to 68.0\%. Furthermore, the "randomization" plan for the order of the eight runs was not adhered to because of time 1 imitations. This deviation from randcm order may have contaminated the results with additional systematic error.

\subsection{Anomalies Observed}

The only unexpected stream compositions were observed in ACR-43, in which the exit liquid stream from the SRP was more concentrated in acid than the EDP bottoms (2.8 vs $2.5 \%)$. This violates the law of conservation of mass and results in the 1 iquid-phase efficiency $\eta_{L, S R P}$ having a negative value.

There are several possible explanations for this "inverted mass balance." First, the composition values are fairly close, and might lie within the range of true experimental error (especially at the low acid level). Alternatively, the shift could be due to a real effect. Perhaps the azeotropic composition is not $0 \% \mathrm{HN}_{3}$, but actually is above the SRP composition. [Cigna et al. (2) reported that $45 \mathrm{wt} \% \mathrm{Mg}\left(\mathrm{NO}_{3}\right)_{2}$ is required to completely el iminate the azeotrope.] This would cause water to be boiled off before nitric acid, producing the observed effect.

\subsection{Computer Model}

The program was implemented onto the PLP-10 system and was believed to be completely debugged. Suveral tasks still renain before the progran may be used, however. It mist be shown that the model will actually converge (see Appendix 11.7) o.n a unique SRP effluent flow rate and compostition for any set of operating conditions. When this convergence is proved, the ability of the computer model to duplicate observed conditions must be evaluated. Only then can the simulation be used with confidence. 


\section{COMCLUSIONS}

1. The effects of four controlled factors, EDP temperature, EDP volune, acid feed rate, and solvent recycle rate, on several response variables were ordered. Linear expressions for the response parameters as functions of the controlled factors were developed.

2. The CPRR and CCP are the most important response parameters in scaleup. CPRR increases with EDP volume and temperature, while CCP decreases with EDP temperature.

3. Stage efficiencies are not as useful in scaleup but are used in the theoretical model to predict the CPRR and CCP. The liquid-phase efficiency is an increasing function of EDP temperature while the vaporphase efficiency increases with acid flow rate and decreases with EDP volune and solvent recycle rate.

4. A greater range of controlled factors must be stujied to fully determine their effect on the system. problem.

5. The two-pot system may be better represented as a mass transfer

\section{RECOMENDATIONS}

Recomendations for further study on the two-pot nitric acid dehydration proposal are:

1. Obtain an estimate of overall experimental error for the twh-pot system by conducting a series of dupicate runs. Use this error anciysis to determine whether the observed effects are statistically significant.

2. Study the effect of other variables, especially SRP temperature and volume, on the response variables.

3. Study extended variable ranges. In particular, investigate lower EDP temperatures $\left(2130^{\circ} \mathrm{C}\right)$ and much lower magnesium nitrate flow rates (<25 cc/min).

4. Redesign the system to permit a direct study of the mass transfer aspects. Other feed-tube designs and baffles to produce smaller bubbles are suggested.

5. Improve and extend existing equilibrium data with a complete literature search. An experimental study may be necessary to accurately determine isotherms. 
6. Refine computer model by:
a) developing more complete correlations for the SRP efficiencies after relevant factors are studied;
b) improving the data base;
c) developing a convergence routine that can determine the optimal values for the SRP effluent stream;
d) verifying the model by comparing its predictions to observed steady-state operating conditions.

\section{ACKNOHLEDGMENTS}

We thank the following persons for their valuable assistance during the project: Pete Counce, Tom Hebble, K.C. Lannom, Jack Marley, Lee Thompson, and Marvin thatley. 


\section{APPERDIX}

\subsection{Experimental Data}

Table 7 is a compilation of the data which were collected in the eight runs of the factorial design. From this basic information all response factors were calculated.

Table 7. Experimental Results

Conditions for Run ACR-42

$\begin{array}{ll}T_{E D P} & =155^{\circ} \mathrm{C} \\ V_{E D P} & =800 \mathrm{cC} \\ F_{M g}\left(\mathrm{NO}_{3}\right)_{2} & =65 \mathrm{cc} / \mathrm{min} \\ F_{\text {figed }} & =11.5 \mathrm{cc} / \mathrm{min}\end{array}$

Stream Parameters

(wt \%) F $\quad$ F $\quad$ G

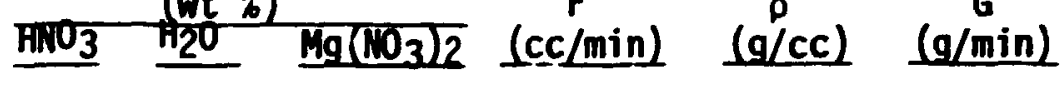

Feed $64.8 \quad 35.2$

Concentrated product 69.2

30.8

0.0 $11.5 \quad 1.389$ 16.0 Dilute product 55.1

44.9

0.0

8.7

12.1

SRP bottoms

$1.0 \quad 53.5$

0.0

2.5

54.1

45.5

3.1

EDP bottoms

43.4

65.0 100.6

Conditions for Run ACR-43

$\begin{array}{ll}T_{\text {EDP }} & =155^{\circ} \mathrm{C} \\ V_{E D P} & =800 \mathrm{cc} \\ F_{\text {Mg }}\left(\mathrm{NO}_{3}\right)_{2} & =16 \mathrm{cc} / \text { min } \\ F_{\text {feed }} & =50 \mathrm{cc} / \mathrm{min}\end{array}$

Feed 65.1

Concentrated product

Dilute product

SRP bottoms

67.6

34.9

0.0

16.0

1.390

$10.5 \quad 1.397$

$49.5 \quad 50.5$

$2.8 \quad 53.5$

0.0

2.0

1.298

22.1

EDP bottoms

$2.5 \quad 53.5$

43.7

44.0

$50.0 \quad[1.629]$

14.7

2.6

82.0

[ ] = experimentally determined density.

$\star$ = not measured 
Table 7 (continued)

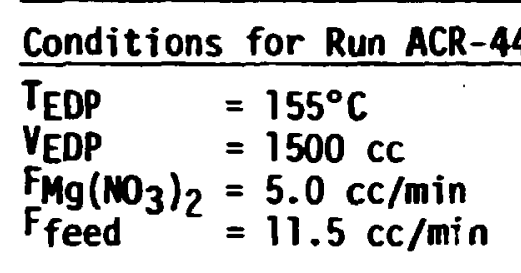

Stream Parameters

\begin{tabular}{|c|c|c|c|c|c|}
\hline \multicolumn{3}{|c|}{ (ut \%) } & \multirow{2}{*}{$\begin{array}{c}F \\
\text { (cc/min) }\end{array}$} & \multirow{2}{*}{$\begin{array}{c}\rho \\
(g / c c)\end{array}$} & \multirow{2}{*}{$\stackrel{\text { G }}{\text { (g/min) }}$} \\
\hline $\mathrm{HMO}_{3}$ & $\mathrm{H} 2 \mathrm{O}$ & $\mathrm{Mg}_{\mathrm{g}}\left(\mathrm{CO}_{3}\right)_{2}$ & & & \\
\hline $\begin{array}{r}65.5 \\
66.8 \\
45.1 \\
1.7 \\
2.9\end{array}$ & $\begin{array}{l}34.5 \\
33.2 \\
54.9 \\
52.9 \\
53.1\end{array}$ & $\begin{array}{r}0.0 \\
0.0 \\
0.0 \\
45.4 \\
44.0\end{array}$ & $\begin{array}{c}11.5 \\
8.7 \\
2.0 \\
\star \\
50.0\end{array}$ & $\begin{array}{c}1.389 \\
1.392 \\
1.276 \\
\star \\
1.629\end{array}$ & $\begin{array}{r}16.0 \\
12.1 \\
2.6 \\
78.9 \\
81.5\end{array}$ \\
\hline
\end{tabular}

Conditions for Run ACR-45

$\begin{array}{ll}T_{E D P} & =155^{\circ} \mathrm{C} \\ \mathrm{V}_{\mathrm{EDP}} & =1500 \mathrm{cC} \\ \mathrm{F}_{\text {Mg }}\left(\mathrm{NO}_{3}\right)_{2} & =65 \mathrm{cc} / \mathrm{min} \\ \mathrm{F}_{\text {feed }} & =16 \mathrm{cc} / \mathrm{min}\end{array}$

$\begin{array}{lrrrrrr}\text { Feed } & 65.5 & 34.5 & 0.0 & 16.0 & 1.380 & 22.1 \\ \text { Conc. product } & 67.5 & 32.5 & 0.0 & 14.3 & 1.390 & 19.9 \\ \text { Dilute product } & 45.2 & 54.8 & 0.0 & 2.7 & 1.270 & 3.4 \\ \text { SRP bottoms } & 1.5 & 54.2 & 44.3 & \star & \star & 104.3 \\ \text { EDP bottoms } & 3.0 & 53.3 & 43.7 & 65.0 & 1.626 & 105.7\end{array}$

Conditions for Run ACR-46

$T_{E D P}=140^{\circ} \mathrm{C}$

$V_{\text {EDP }}=1500 \mathrm{cc}$

$\mathrm{FMg}_{\mathrm{MO}}\left(\mathrm{NO}_{3}\right)_{2}=50 \mathrm{cc} / \mathrm{min}$

$F_{\text {feed }}=16 \mathrm{cc} / \mathrm{min}$

$\begin{array}{lrrrrrr}\text { Feed } & 66.1 & 33.9 & 0.0 & 16.0 & 1.396 & 22.3 \\ \text { Conc. product } & 77.9 & 22.1 & 0.0 & 8.8 & 1.445 & 12.7 \\ \text { Dilute product } & 51.8 & 48.2 & 0.0 & 7.9 & 1.321 & 10.4 \\ \text { SRP bottoms } & 2.2 & 53.6 & 44.2 & \star & \star & 71.5 \\ \text { EDP bottoms } & 7.6 & 52.9 & 39.5 & 50.0 & 1.600 & \mathbf{8 0 . 0}\end{array}$


Conditions for Run ACR-47

$\begin{aligned} T_{\text {EDP }} & =140^{\circ} \mathrm{C} \\ V_{E D P} & =1500 \mathrm{cC} \\ \mathrm{F}_{M g}\left(\mathrm{MO}_{3}\right)_{2} & =65 \mathrm{cC} / \mathrm{min} \\ \mathrm{F}_{\text {feed }} & =11.5 \mathrm{cc} / \mathrm{min}\end{aligned}$

Stream Paraneters

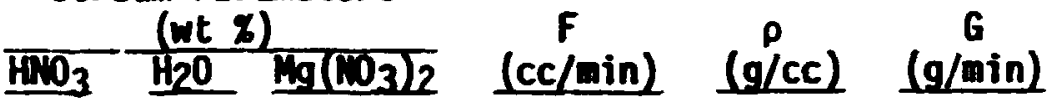

$\begin{array}{lrrrrrr}\text { Feed } & 68.0 & 32.0 & 0.0 & 11.5 & 1.405 & 16.2 \\ \text { Conc. product } & 81.7 & 18.3 & 0.0 & 5.2 & 1.458 & 7.6 \\ \text { Dilute product } & 53.5 & 46.5 & 0.0 & 6.0 & 1.331 & 8.0 \\ \text { SRP bottoms } & 1.3 & 5 . .6 & 45.1 & \star & \star & 91.7 \\ \text { EDP bottoms } & 7.2 & 53.1 & 39.7 & 65.0 & 1.602 & 104.1\end{array}$

Conditions for Run ACR-48

$T_{E D P}=140^{\circ} \mathrm{C}$

$V_{\text {EDP }}=800 \mathrm{cc}$

$\mathrm{FMg}\left(\mathrm{NO}_{3}\right)_{2}=50 \mathrm{cc} / \mathrm{min}$

$F_{\text {feed }}=11.5 \mathrm{cc} / \mathrm{min}$

$\begin{array}{lrrrrrr}\text { Feed } & 67.1 & 32.9 & 0.0 & 11.5 & 1.400 & 16.1 \\ \text { Conc. product } & 81.0 & 19.0 & 0.0 & 3.5 & 1.456 & 5.0 \\ \text { Dilute product } & 58.7 & 41.3 & 0.0 & 7.0 & 1.360 & 9.5 \\ \text { SRP bottoms } & 2.5 & 53.2 & 44.3 & \star & \star & 72.2 \\ \text { EDP bottoms } & 7.8 & 52.4 & 39.8 & 50.0 & 1.602 & \mathbf{8 0 . 2}\end{array}$

Conditions for Run ACR-49

$T_{\text {EDP }}=140^{\circ} \mathrm{C}$

VEDP $=800 \mathrm{cC}$

$\begin{aligned} \mathrm{F}_{\mathrm{feg}}\left(\mathrm{NO}_{3}\right)_{2} & =65 \mathrm{cc} / \mathrm{min} \\ & =16 \mathrm{cc} / \mathrm{min}\end{aligned}$

$\begin{array}{lrrrrrr}\text { Feed } & 63.8 & 36.2 & 0.0 & 16.0 & 1.386 & 22.2 \\ \text { Conc. product } & 82.8 & 17.2 & 0.0 & 6.1 & 1.458 & 8.9 \\ \text { Dilute product } & 53.5 & 46.5 & 0.0 & 10.2 & 1.331 & 13.6 \\ \text { SRP bottoms } & 1.4 & 53.6 & 45.6 & \star & \star & 91.9 \\ \text { EDP bottom } & 7.5 & 52.8 & 39.7 & 65.0 & 1.602 & 104.1\end{array}$


Early in the experimental program an experiment was performed in which the objective was to reproduce one of the runs which had been performed by Counce et al. (1). Of particular interest was a comparison of stream compositions. The feed compositions of the two runs were slightly different; run ACR-38 contained more water. Overhead streams which contained only $\mathrm{HnO}_{3}$ and $\mathrm{H}_{2} \mathrm{O}$ agreed within the analytical error of the experiment (Appendix 11.3 ). The bottoms concentrations showed rather large discrepancies in the $\mathrm{H}_{2} \mathrm{O}$ and $\mathrm{Mg}\left(\mathrm{NO}_{3}\right)_{2}$ concentrations. This is possibly attributable to differences in feed compositions. More likely however is the possibility that one or both runs had not attained steady state or that a measurement or sampling error was made. This comparison is given in Table 8 .

Table 8. Comparison of Performance Results from Runs ACR-10* and ACR-38

\section{Operating Conditions - Both Runs}

$T_{\text {EDP }}=140^{\circ} \mathrm{C}$

$T_{\text {SRP }}=170^{\circ} \mathrm{C}$

$V_{E D P}=1000 \mathrm{cC}$

$V_{\text {SRP }} \cong 1500 \mathrm{cc}$

$$
\begin{aligned}
F_{\mathrm{Mg}\left(\mathrm{NO}_{3}\right)_{2}} & =65 \mathrm{cc} / \mathrm{min} \\
F_{\text {feed }} & =17.3 \mathrm{cc} / \mathrm{min}
\end{aligned}
$$

\begin{tabular}{|c|c|c|c|c|c|c|}
\hline \multirow[b]{2}{*}{ Stream } & \multicolumn{2}{|c|}{$\mathrm{HNO}_{3}$} & \multicolumn{2}{|c|}{$\mathrm{H}_{2} \mathrm{O}$} & \multicolumn{2}{|c|}{$\mathrm{Mg}\left(\mathrm{MO}_{3}\right)_{2}$} \\
\hline & No. $\overline{\text { ACR-10 }}$ & $\overline{A C R-38}$ & ACR-10 & ACR-38 & ACR-10 & ALR-38 \\
\hline Feed & 70.0 & 66.0 & 30.0 & 34.0 & - & - \\
\hline \multicolumn{7}{|l|}{ EDP } \\
\hline $\begin{array}{l}\text { overhead } \\
\text { bottoms }\end{array}$ & $\begin{array}{r}81.0 \\
6.5\end{array}$ & $\begin{array}{r}83.0 \\
6.1\end{array}$ & $\begin{array}{l}19.0 \\
33.4\end{array}$ & $\begin{array}{l}17.0 \\
52.6\end{array}$ & $6 \overline{0} .1$ & $\overline{41.3}$ \\
\hline \multicolumn{7}{|l|}{ SRP } \\
\hline $\begin{array}{l}\text { overhead } \\
\text { bottoms }\end{array}$ & $\begin{array}{r}53.0 \\
0.6\end{array}$ & $\begin{array}{c}51.0 \\
0\end{array}$ & $\begin{array}{l}47.0 \\
31.7\end{array}$ & $\begin{array}{l}49.0 \\
52.7\end{array}$ & 67.7 & $4 \overline{7} .3$ \\
\hline
\end{tabular}

Stream Concentrations (wt \%)

tData from Counce et al. (1). 
11.2 Sample Set of Analytical Calculations for Run ACR-48

1. Calibration of Nitric Acid Titration

maol $\mathrm{HnO}_{3}=(0.0373 \times$ chart m) -0.0207

See project calculation file for thermographs used in the calibration.

2. $\mathrm{inO}_{3}$ in Feed and Product Streans

$$
\underline{M} \mathrm{MNO}_{3} \text { (noles/liter) }=\operatorname{mol} \mathrm{hmO}_{3} \div \text { aliquot volume }(\mathrm{ml})
$$

\begin{tabular}{|c|c|c|c|c|c|c|c|}
\hline Stream & Sample & & $\begin{array}{c}\text { Al iquot } \\
(\lambda \ell)\end{array}$ & $\begin{array}{l}\text { Chart } \\
\text { (min) }\end{array}$ & $\begin{array}{c}\mathrm{HNO}_{3} \\
\text { (amolé) }\end{array}$ & $\underline{\underline{M}} \mathrm{HO}_{3}$ & $x_{\mathrm{Hin}_{3}}(\mathrm{x})$ \\
\hline $\begin{array}{l}\text { Feed } \\
\text { Concentrate } \\
\text { Dilute }\end{array}$ & $\begin{array}{l}4.88 \\
480 \\
482\end{array}$ & $\begin{array}{l}\text { a) } \\
\text { b) } \\
\text { a) } \\
\text { b) } \\
\text { a) } \\
\text { b) }\end{array}$ & $\begin{array}{l}50 \\
50 \\
50 \\
50 \\
50 \\
50\end{array}$ & $\begin{array}{l}42.2 \\
42.9 \\
52.4 \\
53.5 \\
36.1 \\
36.6\end{array}$ & $\begin{array}{l}0.7396 \\
0.7524 \\
0.9253 \\
0.9243 \\
0.6286 \\
0.6377\end{array}$ & $\begin{array}{l}14.79 \\
15.05 \\
18.51 \\
18.91 \\
12.57 \\
12.75\end{array}$ & $\begin{array}{l}66.7 \\
6 \pi .5 \\
80.3 \\
81.7 \\
58.2 \\
59.2\end{array}$ \\
\hline
\end{tabular}

Weight fractions $\left(X_{\mathrm{HnO}_{3}}\right)$ were found from molarities $\left(\underline{\mathrm{H}} \mathrm{HHO}_{3}\right)$ using tables from Dean (6).

Average values for feed, product strean (wt \%):

$$
\begin{array}{ll}
\text { feed acid } & 67.1 \\
\text { concentrated product } & =81.0 \\
\text { dilute product } & 58.7
\end{array}
$$

\begin{tabular}{|c|c|c|c|c|c|}
\hline Stream & Sample & $\begin{array}{c}\text { Total Weight } \\
(\mathrm{g})\end{array}$ & $\begin{array}{c}\text { Tared Height } \\
(\mathrm{g})\end{array}$ & $\begin{array}{l}\text { Net Weight } \\
\text { (g) }\end{array}$ & $\begin{array}{c}\text { Yolume } \\
\text { (mi) } \\
\end{array}$ \\
\hline $\begin{array}{l}\text { SRP bottoms } \\
\text { EDP bottoms }\end{array}$ & $\begin{array}{l}484 \\
486\end{array}$ & $\begin{array}{l}47.3246 \\
41.7085\end{array}$ & $\begin{array}{l}30.1073 \\
29.9991\end{array}$ & $\begin{array}{l}17.2173 \\
11.7094\end{array}$ & $\begin{array}{l}200 \\
100\end{array}$ \\
\hline
\end{tabular}

3. Solution Makeup from Recycle Strean Samples 
4. $\mathrm{HnO}_{3}$ in Recycle Streams

\begin{tabular}{|c|c|c|c|c|c|c|c|c|}
\hline Stream & Sample & $\begin{array}{l}\text { Al iquot } \\
(\mathrm{m}))^{2}\end{array}$ & $\begin{array}{l}\text { Spike } \\
\text { Volume } \\
\text { (ml) }\end{array}$ & $\begin{array}{c}\text { Chart } \\
(\mathrm{m})\end{array}$ & $\begin{array}{r}\text { Total } \\
\text { (nin) } \\
(\min 1) \\
\end{array}$ & $\begin{array}{l}\text { Spike } \\
\mathrm{Hmo}_{3} \\
(\mathrm{mmol})\end{array}$ & 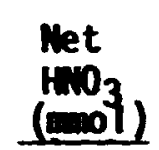 & $\mathrm{X}_{\mathrm{HnO}}$ \\
\hline $\begin{array}{l}\text { SRP bottoms } \\
\text { EDP bottoms }\end{array}$ & $\begin{aligned} & 484 \text { a) } \\
& \text { b) } \\
& 486 \text { a) } \\
& \text { b) }\end{aligned}$ & $\begin{array}{l}5.0 \\
5.0 \\
5.0 \\
5.0\end{array}$ & $\begin{array}{l}500 \\
500 \\
500 \\
500\end{array}$ & $\begin{array}{l}40.8 \\
39.5 \\
72.9 \\
71.4\end{array}$ & $\begin{array}{l}0.6851 \\
0.6626 \\
1.2405 \\
1.2145\end{array}$ & $\begin{array}{l}0.5016 \\
0.5016 \\
0.5016 \\
0.5016\end{array}$ & $\begin{array}{l}0.1835 \\
0.1610 \\
0.7389 \\
0.7129\end{array}$ & $\begin{array}{l}0.0269 \\
0.0236 \\
0.0796 \\
0.0768\end{array}$ \\
\hline \multicolumn{9}{|c|}{$\mathrm{HNO}_{3}(\mathrm{mmol})=(0.0173 \times$ chart $\mathrm{mm})-0.0207-\operatorname{spike}(\mathrm{mmol})$} \\
\hline$x_{\mathrm{HNO}_{3}}=$ & $\mathrm{HNO}_{3}(\mathrm{n}$ & 1) $\left[\frac{63.1}{\mathrm{a} 1}\right.$ & $\frac{g / m o l e}{q u o t(\pi}$ & $\frac{\text { solu }}{x \text { sar }}$ & ion volt & $\frac{n(l)}{h t(g)}$ & & (9) \\
\hline
\end{tabular}

Average values for $\mathrm{HNO}_{3}$ weight percents in recycle streams are:

$$
\begin{aligned}
& \text { SRP bottoms }=2.5 \% \\
& \text { EDP bottoms }=7.8 \%
\end{aligned}
$$

5. Standardization of EDTA Solution for Titration of $\mathrm{Mg}\left(\mathrm{MO}_{3}\right)_{2}$

Aliquot of $\mathrm{Mg}$ Standard EDTA Volume (ml) $M$ (moles/liter)
a)
5.0
9.84
0.05036
b)
5.0
9.86
0.05025

Standard: $2.4088 M$
EDTA concentration $\underline{M}=2.4088 \mathrm{~g} / \ell \div 24.307 \mathrm{~g} / \mathrm{mole} \times$ aliquot $(\mathrm{ml})$$$
\div \text { EDTA volume (mI) }
$$$$
=0.0503
$$

\begin{tabular}{|c|c|c|c|c|c|c|}
\hline Stream & Sample & $\begin{array}{l}\text { Al iquot } \\
\text { (mI) }\end{array}$ & $\begin{array}{l}\text { EDTA Volume } \\
\text { (mi) }\end{array}$ & EDTA M & $\mathrm{Mg}\left(\mathrm{NO}_{3}\right)_{2}$ & $\mathrm{X}_{\mathrm{Mg}\left(\mathrm{NO}_{3}\right)_{2}}$ \\
\hline $\begin{array}{l}\text { SRP bottoms } \\
\text { EDP bottoms }\end{array}$ & $\begin{array}{cc}484 & \text { a) } \\
\text { b) } \\
486 \text { a) } \\
\text { b) }\end{array}$ & $\begin{array}{l}1.0 \\
2.0 \\
1.0 \\
1.0\end{array}$ & $\begin{array}{r}7.57 \\
15.07 \\
9.25 \\
9.20\end{array}$ & $\begin{array}{l}0.0503 \\
0.0503 \\
0.0503 \\
0.0503\end{array}$ & $\begin{array}{l}0.3808 \\
0.3790 \\
0.4653 \\
0.4628\end{array}$ & $\begin{array}{l}0.4437 \\
0.4417 \\
0.3986 \\
0.3965\end{array}$ \\
\hline
\end{tabular}

6. $\mathrm{Mg}\left(\mathrm{NO}_{3}\right)_{2}$ in Recycle Streams 


$$
\begin{aligned}
& \text { M, } \mathrm{Mg}\left(\mathrm{m}_{3}\right)_{2}=\frac{\text { EDTA Volume }(\mathrm{ml}) \times \text { EDTA } M(\mathrm{~mol} / \mathrm{liter})}{\text { aliquot (mI) }} \\
& x_{M g\left(\mathrm{NO}_{3}\right)_{2}}=\frac{\mathrm{mg}\left(\mathrm{m}_{3}\right)_{2}(\text { mol } / \text { liter }) \times 150.32 \mathrm{~g} / \text { mole } \times \text { solution volume }(l)}{\text { sample weight }(\mathrm{g})}
\end{aligned}
$$

Average $\mathrm{Mg}\left(\mathrm{MO}_{3}\right)_{2}$ composition of recycle streams are:

$$
\begin{aligned}
& \text { SRP bottoms }=44.3 \% \\
& \text { EDP bottons }=39.8 \%
\end{aligned}
$$

7. Strean Flon Rates

\section{Stream}

Feed

Concentrated product

Dilute product

SRP bottoms

EDP bottoms

$$
\underline{F(c c / m i n)} \quad 2(g / c c)
$$

$$
11.5
$$$$
3.5
$$$$
7.0
$$

50.0

1.400

1.456

1.360

1.602
$\underline{G}(\mathrm{cc} / \min )$

16.1

5.0

9.5

72.2

80.2

Density data for acid streams (feed and products) were taken from Cean (6). For recycle streams, a correlation based on Rainey's work (7) for the dependences of density on temperature and on $\mathrm{Mg}\left(\mathrm{NO}_{3}\right)_{2}$ concentration was used:

$$
\rho(g / c c)=1.6288-\left(T-155^{\circ} \mathrm{C}\right)\left(8 \times 10^{-4}\right)+\left(x_{3}-0.440\right)(0.90)
$$

8. Concentrated Product Recovery Ratio:

$$
\text { CPRR }=\frac{\mathrm{GHNO}_{3} \text { (concentrate) }}{\mathrm{G}_{\mathrm{HNO}_{3}}(\text { feed })}=\frac{5.0}{16.1}=0.31
$$

9. Concentration of Concentratec Product, $\mathrm{XHNO}_{3}$ (concentrate)

$$
C C P=0.810
$$

\footnotetext{
*Not measured.
} 
10. Mass Balance Check on Results for Run ACR-48

a) $\operatorname{mon}_{3}$

overall: $z$ deviation $=100\left[\frac{G_{1} H_{1,1}-G_{2} W_{2,1}-G_{3} H_{3,1}}{G_{1} W_{1,1}}\right]$

SRP: $q$ deviatio. $=100\left[\frac{G_{4} W_{4,1}-G_{3} W_{3,1}-G_{5} W_{5,1}}{G_{4} W_{4,1}}\right]$

EDP: $z$ deviation $=100\left[\frac{G_{1} W_{1,1}+G_{5} H_{5,1}-G_{2} W_{2,1}-G_{4} W_{4,1}}{G_{1} W_{1,1}}\right]$

b) $\mathrm{H}_{2} \mathrm{O}$

Same as above, with weight fractions for water.

$$
\begin{array}{ll}
\text { Streams: } & 1 \text { - feed } \\
& 2 \text { - concentrate } \\
& 3 \text { - dilute } \\
& 4 \text { - EDP bottoms } \\
& 5 \text { - SRP bottoms }
\end{array}
$$

$$
\text { Components: } \begin{aligned}
& 1-\mathrm{HNO}_{3} \\
& 2-\mathrm{H}_{2} \mathrm{O} \\
& 3-\mathrm{Mg}\left(\mathrm{HO}_{3}\right)_{2}
\end{aligned}
$$

Results

\begin{tabular}{lrcr} 
& \multicolumn{3}{c}{ \% Deviation } \\
\cline { 2 - 5 } & Overall & EDP & SRP \\
$\mathrm{HNO}_{3}$ & 10.9 & 21.3 & 17.9 \\
$\mathrm{H}_{2} \mathrm{O}$ & 8.0 & 11.8 & 4.3
\end{tabular}

\subsection{Estimation of Experimental Error}

This section presents an estimation of experimental error for both measured and calculated quantities. Errors for volumetric flow rates and temperature measurements were made in operating the equipment. The analytical error in determining compositions was made by consul tation with the analytical chemist of CFRF. From these estimates, the error in the mass flow rates, response factors, and mass balances was calculated by using standard methods shown below.

1. Directly Measured Quantities
a) Compositions (weight fractions) $-\varepsilon_{W}=2 \%$ error
b) Volumetric flow rates $(c c / m i n)-\varepsilon_{F}=5 \%$ error 
c) Densities $(g / c c)-\varepsilon_{p}=1 \%$ error

Mass flow rates $[g / m i n)\left(\varepsilon_{G}\right)$ may be calculated from the relationship:

$$
\left(100-\varepsilon_{G}\right)=\left(100-\varepsilon_{\rho}\right)\left(100-\varepsilon_{F}\right)=(99)(95)
$$

Therefore, $\mathscr{E}_{G}=\mathbf{5 . 9 8}$

2. Response Factor

a) CPRR

$$
\left(100-\varepsilon_{C P R R}\right)=\left(100-\varepsilon_{G}\right)^{2} \text {. Therefore } \varepsilon_{C P R R}=11.5 \% \text {. }
$$

b) $\mathbf{C C P}$

$$
\varepsilon_{\text {CCP }}=2.0 \%
$$

c) Stage efficiencies are defined as follows:

$$
n=\frac{w_{1}-z_{1}}{w_{1}^{*}-z_{1}}
$$

Therefore the error in the stage efficiencies is:

$$
\left.100-\varepsilon_{\eta}=[l i]-\sqrt{2} \varepsilon_{w}\right]\left[100-\sqrt{\varepsilon_{w}^{2}+\varepsilon_{*}^{2}}\right]
$$

The error in equilibrium data is:

$$
\varepsilon_{\star}=4.0 \% \text { (average deviation) }
$$

Therefore,

$$
\varepsilon_{\eta}=14.4 \%
$$

3. Mass Balances

a) Overall

$$
\text { \% deviation }=\frac{G_{1} W_{1,1}-G_{2} W_{2,1}-G_{3} W_{3,1}}{G_{1} W_{1,1}}
$$




$$
\begin{aligned}
100-\varepsilon_{G, H} & =\left(100-\varepsilon_{G}\right)\left(100-\varepsilon_{W}\right)=(100-5.9)(100-2.0)(20) \\
\varepsilon_{G, H} & =7.8 \% \\
100-\varepsilon_{d, 0} & =\left[100-\sqrt{3\left(\varepsilon_{G, H}\right)^{2}}\right]\left[100-\varepsilon_{G, H}\right]=[100-13.5][100-7.8] \\
\varepsilon_{d, 0} & =20.2 \%
\end{aligned}
$$

b) SRP

SRP is the same as overall mass balance:

$$
\varepsilon_{d, s}=20.2 \%
$$

c) EDP

$$
\begin{aligned}
\text { \% deviation } & =\frac{G_{1} H_{1,1}+G_{5} H_{5,1}-G_{2} W_{2,1}-G_{4} W_{4,1}}{G_{1} W_{1,1}} \\
100-\varepsilon_{d, E} & =\left[100-\sqrt{4\left(\varepsilon_{G, H}\right)^{2}}\right]\left[100-\varepsilon_{G, H}\right]=[100-15.6][100-7.8] \\
\varepsilon_{d, E} & =22.2 \%
\end{aligned}
$$

11.4 Calculation of Stage Efficiencies

1. Combined Feed: EDP

\begin{tabular}{|c|c|c|c|c|}
\hline & $G(g / m i n)$ & $x_{1}\left(z_{1}\right)$ & $x_{2}$ & $x_{3}$ \\
\hline $\begin{array}{l}\text { Feed acid } \\
\text { SRP bottoms } \\
\text { Combined feed }\end{array}$ & $\begin{array}{l}16.1 \\
72.0 \\
88.1\end{array}$ & $\begin{array}{l}0.671 \\
0.025 \\
0.143\end{array}$ & $\begin{array}{l}0.329 \\
0.532 \\
0.495\end{array}$ & $\begin{array}{c}0 \\
0.443 \\
0.362\end{array}$ \\
\hline
\end{tabular}

G $(g / \min )$

Feed acid

SRP bottoms

Combined feed
Weight Fraction:

$$
\begin{aligned}
& x_{1}, x_{2} \\
& x_{1}, x_{2}, x_{3} \\
& z_{1}, z_{2}, z_{3}
\end{aligned}
$$

The feed compositions for run $A C R-48$ with the temperature at $140^{\circ} \mathrm{C}$ is: 


\section{Calculation of Equilibriu Vapor-Phase Composition}

A computer routine called EQCALC was witten to calculate the equilibrim vapor-phase composition if a liquid-phase composition is given. It is discussed in detail in Appendix 11.7. Using EQCALC, the equilibrium composition of the vapor phase exiting the EDP was calculated. This was done by inputting the combined feed (SRP bottoms and feed acid) and EDP temperature, and using the appropriate equilibrium data file (see sect. 5). The results of this calculationare given in Table 9.

Table 9. Equilibrium Product Composition - EDP Feeds Run ACR-48

\begin{tabular}{lccc}
\hline & \multicolumn{3}{c}{ Weight Fraction } \\
\cline { 2 - 4 } Strean & $1-\mathrm{HrO}_{3}$ & $2-\mathrm{H}_{\mathrm{C}} \mathrm{O}$ & $3-\mathrm{Mg}\left(\mathrm{MO}_{3}\right)_{2}$ \\
Combined feed & 0.143 & 0.495 & 0.362 \\
Equilibrium vapor product & 0.318 & 0.682 & 0.00 \\
Equilibrium liquid product & 0.060 & 0.406 & 0.534 \\
\hline
\end{tabular}

3. Calculation of Hansen Stage Efficiencies for the Extractive-Distillation Pot $\left(n_{V, E D P}, n_{L, E D P}\right)$

$$
\begin{aligned}
& n_{V, E D P}=\frac{Y_{1}-Z_{1}}{Y_{1}^{*}-Z_{1}}(100 \%)=\frac{0.810-0.143}{0.318-0.143}(100)=381 \% \\
& n_{L, E D P}=\frac{x_{1}-Z_{1}}{x_{1}^{*}-Z_{1}}(100 \%)=\frac{0.078-0.143}{0.060-0.143}(100)=78 \%
\end{aligned}
$$

It should be stressed that both stage efficiencies were defined by using the combined feed stream $\left(Z_{1}\right)$. It is customary to define an efficiency for a single phase, but this was not possible for the vapor efficiency. Therefore, the combined feed was used to calculate both efficiencies although it is actually at least partially liquid.

4. Feed to SRP (EDP Bottoms) and Computer Calculation of Flash Compositions

The calculation of the compositions at equilibrium of the streams associated with the SRP was performed in an analogous manner to the calculation technique used in the preceding section. Table 10 gives a summary of the results. In this case there is a single feed to the pot. 


$$
\begin{aligned}
100-\varepsilon_{G, H} & =\left(100-\varepsilon_{G}\right)\left(100-\varepsilon_{H}\right)=(100-5.9)(100-2.0)(20) \\
\varepsilon_{G, H} & =7.8 x \\
100-\varepsilon_{d, O} & =\left[100-\sqrt{3\left(\varepsilon_{G, H}\right)^{2}}\right]\left[100-\varepsilon_{G, H}\right]=[100-13.5][100-7.8] \\
\varepsilon_{d, 0} & =20.28
\end{aligned}
$$

b) SRP

SRP is the same as overall mass balance:

$$
\varepsilon_{d, S}=20.2 \%
$$

c) EDP

$$
\begin{aligned}
\text { \% deviation } & =\frac{G_{1} H_{1,1}+G_{5} H_{5,1}-G_{2} H_{2,1}-G_{4} H_{4,1}}{G_{1} H_{1,1}} \\
100-\varepsilon_{d, E} & =\left[100-\sqrt{4\left(\varepsilon_{G, H}\right)^{2}}\right]\left[100-\varepsilon_{G, H}\right]=[100-15.6][100-7.8] \\
\varepsilon_{d, E} & =22.2 \%
\end{aligned}
$$

\begin{tabular}{|c|c|c|c|}
\hline$G(g / m i n)$ & $x_{1}\left(z_{1}\right)$ & $x_{2}$ & $x_{3}$ \\
\hline $\begin{array}{l}16.1 \\
72.0 \\
88.1\end{array}$ & $\begin{array}{l}0.671 \\
0.025 \\
0.143\end{array}$ & $\begin{array}{l}0.329 \\
0.532 \\
0.495\end{array}$ & $\begin{array}{c}0 \\
0.443 \\
0.362\end{array}$ \\
\hline
\end{tabular}

\subsection{Calculation of Stage Efficiencies}

1. Combined Feed: EDP

\begin{tabular}{ll}
$G(g / \min )$ & Weight Fractions \\
\hline Feed acid & $x_{1}, x_{2}$ \\
SRP bottoms & $x_{1}, x_{2}, x_{3}$ \\
Combined feed & $z_{1}, z_{2}, z_{3}$
\end{tabular}

The feed compositions for run $A C R-48$ with the temperature at $140^{\circ} \mathrm{C}$ is:

Feed acid SRP bottoms Combined feed 


\section{Calculation of Equilibrium Vapor-Phase Composition}

A computer routine called EQCALC was written to calculate the equilibrium vapor-phase composition if a liquid-phase composition is given. It is discussed in detail in Appendix 11.7. Using EQCALC, the equilibrium composition of the vapor phase exiting the EDP was calculated. This was done by inputting the combined feed (SRP bottons and feed acid) and EDP temperature, and using the appropriate equilibriun data file (see sect. 5). The results of this calculationare given in Table 9.

Table 9. Equilibrium Product Composition - EDP Feeds Run ACR-48

Strean

Combined feed

Equilibrium vapor product

Equilibriun liquid product

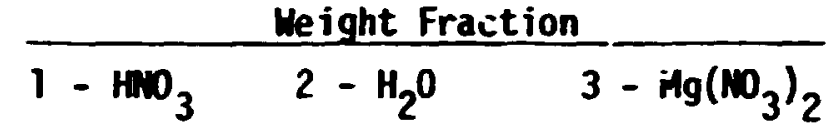
0.143
0.495
0.362

0.318

0.682

0.00

0.406

0.534

3. Calculation of Hansen Stage Efficiencies for the Extractive-Distiliation Pot $\left(\eta_{V, E D P}, \eta_{L, E D P}\right)$

$$
\begin{aligned}
& n_{V, E D P}=\frac{Y_{1}-Z_{1}}{Y_{1}^{\star}-Z_{1}}(100 \%)=\frac{0.810-0.143}{0.318-0.143}(100)=381 \% \\
& n_{L, E D P}=\frac{X_{1}-Z_{1}}{X_{1}^{\star}-Z_{1}}(100 \%)=\frac{0.078-0.143}{0.060-0.143}(100)=78 \%
\end{aligned}
$$

It should be stressed that both stage efficiencies were defined by using the combined feed stream $\left(z_{1}\right)$. It is customary to define an efficiency for a single phase, but this was not possible for the vapor efficiency. Therefore, the combined feed was used to calculate both efficiencies altho'sgh it is actually at least partially liquid.

4. Feed to SRP (EDP Bottoms) and Computer Calculation of Flash Compositions

The calculation of the compositions at equilibrium of the streams associated with the SRP was performed in an analogous manner to the calculation technique used in the preceding section. Table 10 gives a sumary of the results. In this case there is a single feed to the pot. 
Table 10. Equilibrium Product Compositions - SRP Feed Run ACR-48

Stream

SRP feed

Equilibrium vapor product

Equilibrium liquid product
(1) $\mathrm{HWO}_{3}$

0.078

0.197

0.025
Weight Fraction

(2) $\mathrm{H}_{2} \mathrm{O} \quad$ (3) $\mathrm{Fg}\left(\mathrm{KO}_{3}\right)_{2}$

0.528

0.398

0

0.653

From these results one can compute stage efficiencies for the nitric acid:

$$
n_{V, S R P}=\frac{Y_{1}-Z_{1}}{Y_{\star}-Z_{1}}(100)=\frac{0.587-0.078}{0.197-0.078}(100)=429 \%
$$

The jiquid-phase Hansen efficiency for the SRP is defined as:

$$
n_{L, S R P}=\frac{x_{1}-Z_{1}}{x_{1}^{*}-Z_{1}}(100)=\frac{0.025-0.078}{0.025-0.078}(100)=100 \%
$$

\subsection{Statistical Analysis}

For each experimental run the adjustable parameters were set to the low or high values $(-,+)$ as specified by the factorial design. The effect of each parameter on the response factors was determined by taking the average difference of the facturs corresponding to the high and low levels. The average results of this analysis for each response factor and parameter are presented in Table 1?. The average ffect for a typical rasponse factor (CPRR, $\nabla_{\text {EDP }}$ ) is:

$$
\text { net effect }=\left[\frac{(\Sigma+)-(\Sigma-)}{4}\right]=\frac{270-214}{4}=14.0
$$


Table 11. Net Effect of Parameter Effects on Response Factors

\begin{tabular}{|c|c|c|c|c|c|c|}
\hline $\begin{array}{l}\text { Response } \\
\text { Factor } \\
\end{array}$ & $v_{\text {EDP }}$ & $F_{\text {feed }}$ & $\mathrm{F}_{\mathrm{Mg}\left(\mathrm{NO}_{3}\right)_{2}}$ & $T_{\text {EDP }}$ & $V_{\text {EDP }} \cdot F_{\text {feed }}$ & $\mathrm{V}_{\mathrm{EDP}} \cdot \mathrm{F}_{\mathrm{Mg}\left(\mathrm{NO}_{3}\right)_{2}}$ \\
\hline CPRR & 14.0 & 5.5 & 6.0 & 33.5 & -3.5 & 6.0 \\
\hline CСP & -1.7 & 2.0 & -0.7 & -13.1 & 0.3 & -0.8 \\
\hline$\eta_{V, E D P}$ & -100 & 123 & -127 & -38 & -11.8 & 9.8 \\
\hline$\eta_{L, E D P}$ & -1.8 & -8.8 & 8.8 & 28.8 & 6.8 & 4.8 \\
\hline$n_{V, S R P}$ & -666 & 154 & -171 & 1043 & 52 & -17.5 \\
\hline$n_{L, S R P}$ & 25.7 & 40.7 & -22.7 & -43.7 & -30.2 & 26.2 \\
\hline
\end{tabular}

To determine whether an observed change indicated a significant effect, the changes in response factors were expressed in percentage form as given in Table 12. Error estimates were made for each factor as shown in Table 13. These were based solely on uncertainties incurred in analytical work; provision for additional system error was made with a multiplication factor of 1.5. The $50 \%$ factor which attempts to account for the experimental system error is arbitrary. Inherent in our design is a forsaking of any ability to estimate experimental error. This is an area in which further work is indicated. By comparing the error estimated with the response factor changes shown in Table 12, the parameters that had significant effects on each factor could be determined. These are tabulated in order of decreasing importance to the respective variables.

Table 12. Percentage Changes in Response Factors

\begin{tabular}{|c|c|c|c|c|c|c|}
\hline Parameter & CPRR & $\mathrm{CCP}$ & $\eta_{V, E D P}$ & $\eta_{\mathrm{L}, \mathrm{EDP}}$ & $\eta_{V, S R P}$ & $\eta_{L, S R P}$ \\
\hline$V_{\text {EDP }}$ & 26.2 & -2.2 & -23.9 & -1.9 & -49.9 & 34.4 \\
\hline$F_{\text {feed }}$ & 9.5 & 2.7 & 40.1 & -9.0 & 16.7 & 59.8 \\
\hline $\mathrm{F}_{\mathrm{Mg}\left(\mathrm{NO}_{3}\right)_{2}}$ & 10.4 & -1.0 & -29.4 & 9.8 & -15.7 & -22.8 \\
\hline$T_{\text {EDP }}$ & 76.6 & -16.2 & -9.7 & 36.3 & -214 & -39.6 \\
\hline$V_{\text {EDP }} \cdot F_{\text {feed }}$ & -5.6 & 0.1 & -3.1 & 6.7 & 5.3 & -29.2 \\
\hline$V_{E D P} \cdot F_{M g}\left(\mathrm{NO}_{3}\right)_{2}$ & 10.4 & -1.1 & 2.7 & 5.2 & -1.7 & 34.8 \\
\hline
\end{tabular}


Table 13. Error Estimates and Significant Effects

\begin{tabular}{|c|c|c|c|}
\hline Response & $\begin{array}{c}\text { Analytical } \\
\text { Error } \\
(y) \\
\end{array}$ & $\begin{array}{l}\text { Total Error (q) } \\
\text { (1.5 } \times \text { analytical) }\end{array}$ & $\begin{array}{l}\text { Significant Effects } \\
\text { (in order of importance) }\end{array}$ \\
\hline CPRR & \pm 9.8 & \pm 14.7 & $T_{E D P}, V_{E D P}$ \\
\hline CCP & 2.0 & 3.0 & $T_{E D P}$ \\
\hline${ }^{\eta} V$, EDP & 14.4 & 21.6 & $F_{\text {feed }}, F_{\mathrm{Mg}\left(\mathrm{NO}_{3}\right)_{2}}, V_{\text {EDP }}$ \\
\hline$\eta_{L, E D P}$ & 14.4 & 21.6 & $T_{\text {EDP }}$ \\
\hline$n_{V, S R P}$ & 14.4 & 21.6 & $T_{E D P}, V_{E D P}$ \\
\hline$n_{L, S R P}$ & 14.4 & 21.6 & $\begin{array}{l}F_{\text {feed }}, T_{\text {EDPP }}, V_{\text {EDP }} \cdot F_{\mathrm{Mg}\left(\mathrm{NO}_{3}\right)_{2}} \\
V_{\text {EDP }}, V_{\text {EDP }} \cdot F_{\mathrm{Mg}\left(\mathrm{NO}_{3}\right)_{2}}\end{array}$ \\
\hline
\end{tabular}

Expressions were developed for each response factor as a linear function of the corresponding significant parameters:

$$
\begin{aligned}
& C P R R=0.010\left(V_{E D P}-800 \mathrm{cC}\right)+1.1\left(T_{E D P}-140^{\circ} \mathrm{C}\right)+49 \\
& C C P=-0.87\left(T_{E D P}-140^{\circ} \mathrm{C}\right)+81 \\
& \eta_{V, E D P}=9.1\left(F_{\text {feed }}-11.5 \mathrm{cc} / \mathrm{min}\right)-0.047\left(V_{E D P}-800 \mathrm{cc}\right) \\
& -2.8\left(\mathrm{~F}_{\mathrm{Mg}\left(\mathrm{NO}_{3}\right)_{2}}-50 \mathrm{cc} / \mathrm{min}\right)+390 \\
& \eta_{L, E D P}=1.9\left(T_{E D P}-140^{\circ} \mathrm{C}\right)+79 \\
& \eta_{V, S R P}=69\left(T_{E D P}-140^{\circ} \mathrm{C}\right)-0.95\left(V_{E D P}-800 \mathrm{cc}\right)+1800 \\
& \eta_{L, S R P}=-2.9\left(T_{E D P}-140^{\circ} \mathrm{C}\right)+0.040\left(V_{\text {F.DP }}-800 \mathrm{cC}\right)+9.0\left(F_{\text {feed }}\right.
\end{aligned}
$$

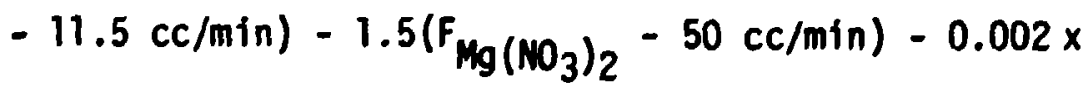

$$
\begin{aligned}
& \left(V_{E D P} F_{\text {feed }}-V_{E D P}^{\circ} F_{\text {feed }}^{\circ}\right)-0.0004\left(V_{E D P} F_{M g}\left(\mathrm{NO}_{3}\right)_{2}\right. \\
& \left.-V_{\mathrm{EDP}}^{\circ} F_{\mathrm{Mg}\left(\mathrm{NO}_{3}\right)_{2}}^{\circ}\right)+530
\end{aligned}
$$


Obviously the data allow no more than a linear relationship in each variable. Therefore a simple graphical analysis was performed.

\subsection{Analytical Laboratory Procedures}

Composition determination of samples included titrations for $\mathrm{HNO}_{3}$ and $\mathrm{Mg}\left(\mathrm{NO}_{3}\right)_{2}$ content. The $\mathrm{HHO}_{3}$ titrations were of the thermometric type, while those for $\mathrm{Mg}\left(\mathrm{NO}_{3}\right)_{2}$ were calorimetric.

The acid feed and overhead products were assumed to be binaries and were analyzed for $\mathrm{HNO}_{3}$ only. This was done with a thermometric titrator that mechanically pumps $\mathrm{NaOH}$ solution $(0.5 \mathrm{M})$ into the acid sample. The temperature rise of reaction was monitored on a strip chart; this change was sharp as the neutralization began, followed a roughly linear path, then stopped abruptly as the reaction endpoint was reached. Samples were transferred to the reaction beaker by micropipetting and were diluted to about $1 \mathrm{cc}$. Approximately $20 \mathrm{cc}$ of potassium fluoride solution (4.5 M) was added to form complexes with $\mathrm{Mg}^{++}$ions, permitting true determination of free acid concentration.

The titrator was calibrated with a nitric acid standard of known concentration. The amount of base added was related to distance on the strip chart. As the moles of base added is equivalent to the moles of acid present, this calibration gives a linear relation between strip-chart distance and moles of acid in solution. Standard samples of 1.0 and 0.5 mmoles were usually used; product acid samples of 50-100 microliters were used to lie within the calibration region.

The EDP and SRP bottoms streams include significant amounts of $\mathrm{Mg}\left(\mathrm{NO}_{3}\right)_{2}$ and are solids at room temperature. Solutions of known volume must be diluted with distilled water. These were analyzed for $\mathrm{HNO}_{3}$ as before. However, acid content was $10 \mathrm{w}(<5 \%)$ and an al iquot of standardized $\mathrm{HNO}_{3}$ (about 0.5 mmoles) had to be added before titration. This kept the total determination in the range of the calibration points, where the linear fit is most reliable.

These variations were analyzed further for $\mathrm{Mg}\left(\mathrm{NO}_{3}\right)_{2}$ concentration by calorimetric methods. Disodium ethylenediaminetetraacetate (EDTA) of $0.05 \mathrm{M}$ concentration was used to titrate the $\mathrm{Mg}^{++}$ions. Samples were poured into a beaker, diluted to about $80 \mathrm{ml}$, and treated with about $5 \mathrm{ml}$ of a $\mathrm{NH}_{4}^{+}$buffer solution to a $\mathrm{pH} \mathrm{10.5}$, where the $\mathrm{Mg}^{++}$EDTA complex is most stable.

One or two drops of Black $T$ (Erichrome Black) was used as the indicator. The initially rose-colored solution turned violet as the endpoint was approached, and it became royal blue when the reaction went to completion. This procedure was most reliable for a content of $\mathrm{Mg}^{++}$ions not greater than $25 \mathrm{mg}$; this corresponds to $20 \mathrm{ml}$ of EDTA required for titration. (If this level was exceeded, the analysis was repeated with a smaller aliquot.) 
Stream densities are required for mass flow rate determinations and system mass balances. As the flon rates read from the experimental apparatus are volumetric for the acid streams, $1.0 \mathrm{ml}$ of each sample was drawn and weighed on an analytical balance.

Pycnometers were initially used to driw samples for density deterninations of the ternary system at operating temperature. Several data points were taken and reported in Appendix 11.1; however, a complete set of data were not taken because the technique required new jars for each test and the laboratory's supply was exhausted. In cases where density data were not measured directly, they were estimated from existing ternary data and some extrapolations based on known binary information. Appendix 1?.1 gives detail on the required calculations.

\subsection{Computer Mode 1}

Section 7.4 was devoted to a discussion of a Fortran program which was written and implemented on the ORNL PDP-10 computer system. The computer flowsheet is presented in Fig. 8, and a list of the program along with the subroutines is given on the following pages.

The calculations required to determine the steady-state conditions for a given set of controllable parameters (see Sect. 4.3.2) are highly iterative due to the large number of unknowns. Initially, values for the mass flow rate and composition of strean 10 (the SRP effluent of Figs. 7 and 8) are assumed, permitting the straightforward calculation of all flow rates and compositions, including new values for stream 10 . The original guess is then modified by the operator until (1) the recycle mass flow rate (stream 6) equals the desired value, and (2) the calculated composition and mass flow rate for stream 10 equals the guessed values.

The first step in the main program (THOPOT) is initialization, in which the controllable parameters are specified, and points lying on equilibrium isotherms for the ternary system are read into the equilibrium-data matrices (EQDATI and EQDAT2). A listing also follows of the points for three isotherms $\left(140,155\right.$, and $165^{\circ} \mathrm{C}$ ) stored in data files (FORXX.DAT) 40 , 55 , and 60 , respectively.

The mass flow rate and composition of stream 10 is then specified by the operator. Stream 10 is then combined with stream 1 (feed acid) with sample component mass balances, resulting in stream 2. The vapor and liquid streams resulting from an isothermal and isobaric equilibrium flash of stream 2 are then determined by subroutine EQSTAG. This calculation is iterative; 1iquid-phase product compositions are assumed, permitting the determination of the vapor-phase composition by using the correlations developed by Eigna et al. (2). A linear fit in the region of 35-45 wt \% $\mathrm{Mg}\left(\mathrm{NO}_{3}\right)_{2}$ is used to calculate the azeotropic $\mathrm{HNO}_{3}$ mole fraction, which is no longer zero if $\mathrm{Mg}\left(\mathrm{NO}_{3}\right)_{2}$ wt \% drops below 45 . Unfortunately, there exist no correlations for solution temperature as a function of composition. Consequently, trial liquid-phase compositions must lie on the 


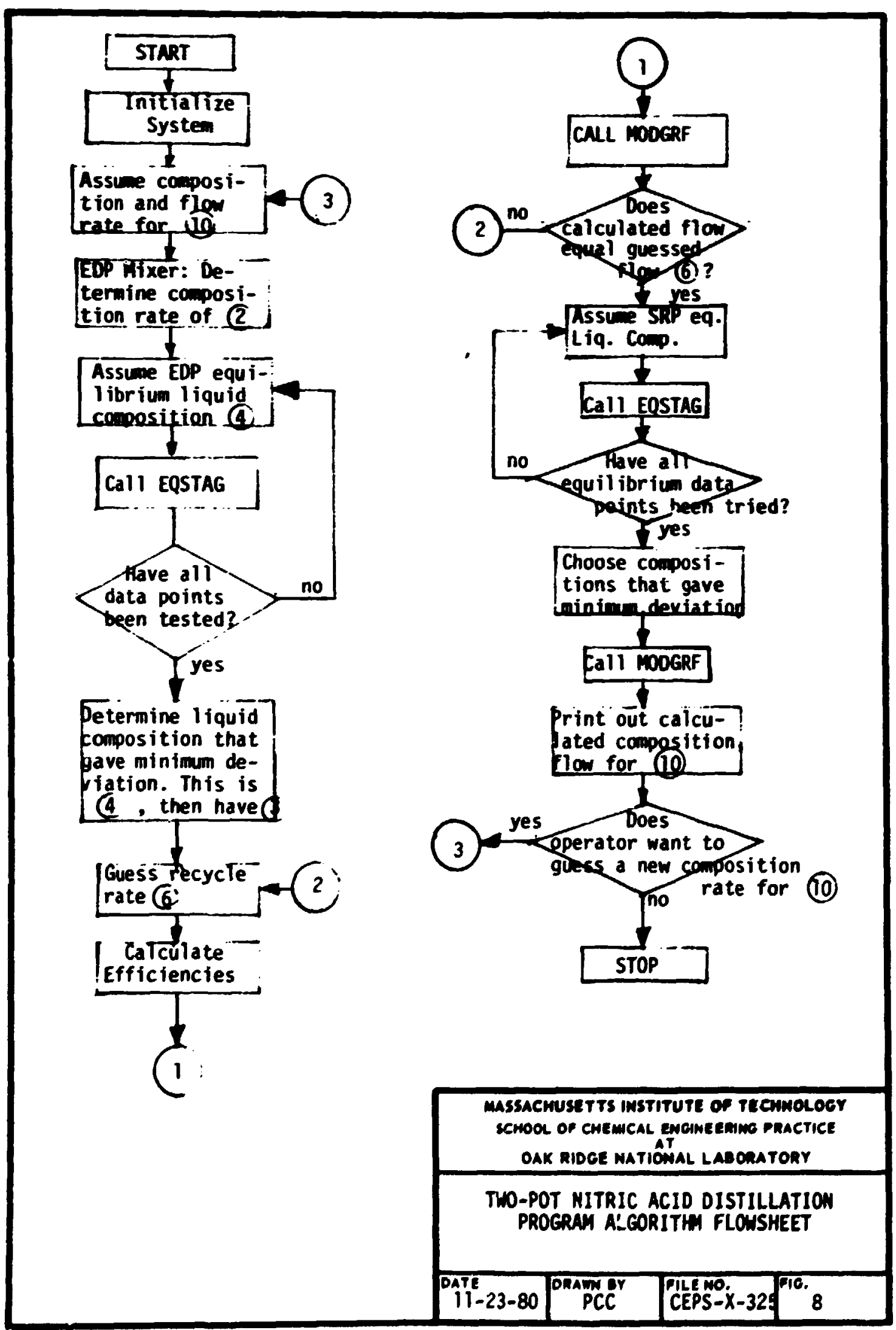




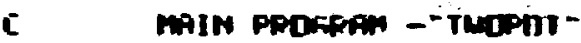

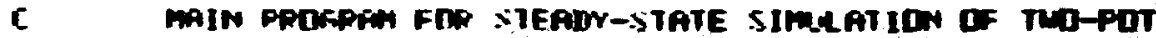

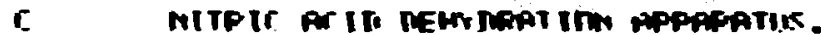

c. WITTEN EY IF IPMIN. II/Q0

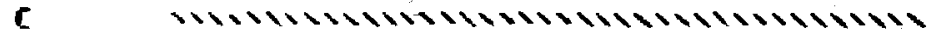

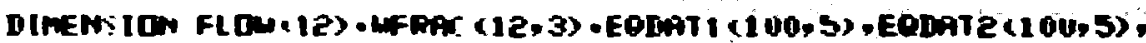

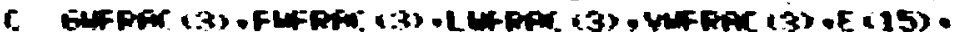

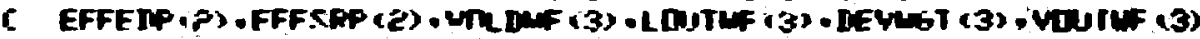

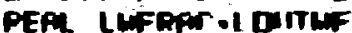

COA-cen IMPIT THF FRCTRP LEVELS

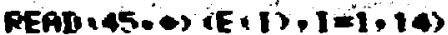

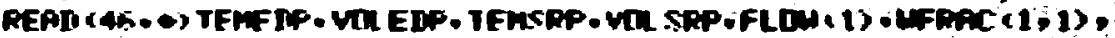

C FLIFEC. INFTFI -IIATFP-IPPINT, LPFPL-LPEP?

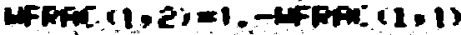

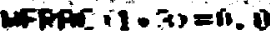

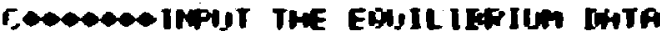

PEATRITATHI $\rightarrow$ LLISTI

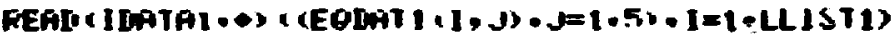

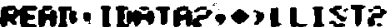

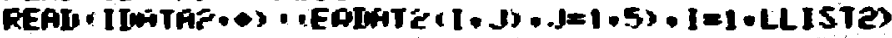

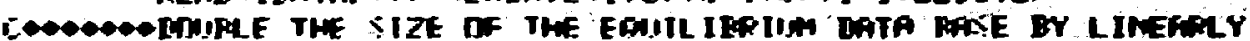

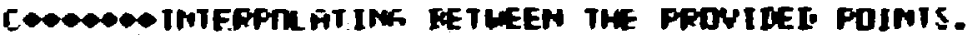

IF ILEFI. EQ. I, 36070 10

ID 15 MPNS=1.11 ISTI-1

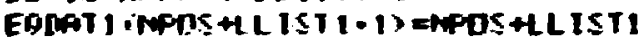

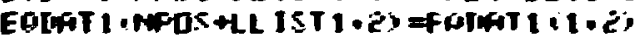

to $15.1=3.5$

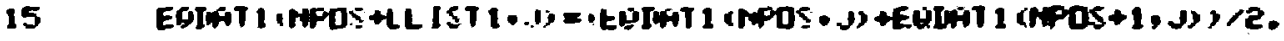

10 IF CI.REPE.EA. 13 SIITO 11

IO is MOSE= I.LLISTE-1

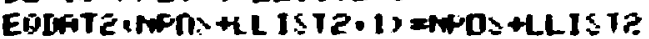

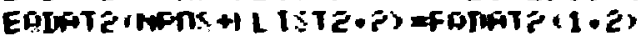

In if $y=2.5$

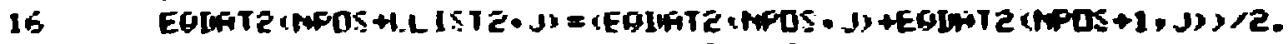

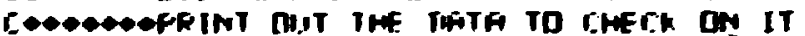

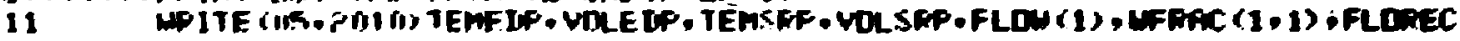

IF ILFEP 1. EO. I ISTOPI ILLISTI

IF RFEFE.EO. ILLTREZA.LISTE

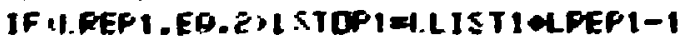

IF CLFEPE.EQ.EOLSTOFE=LL ISTEALEFË-1

IF: IPFINT. ME. 1 Y

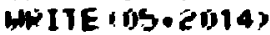

WPITF (115.

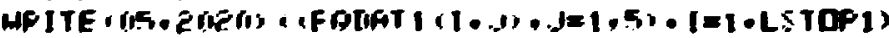

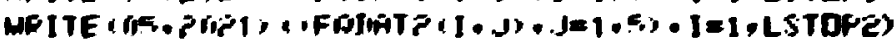


$-1447$

$\therefore x^{2}+4$

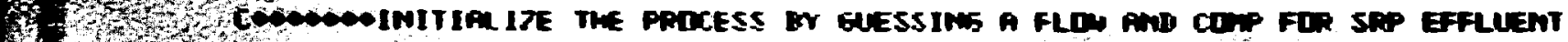

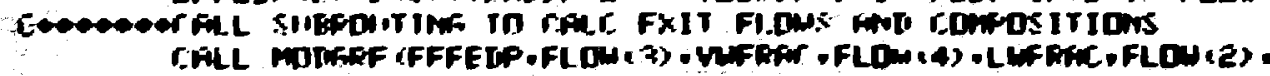

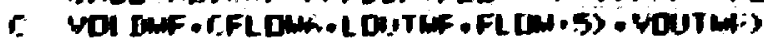




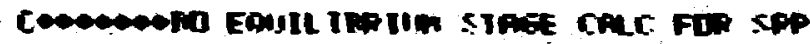

Bo ata m. IST $=1-1$ stgpe

DD $410 I=1 \cdot 3$

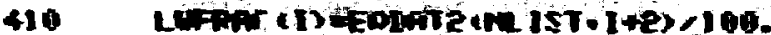

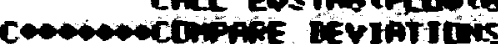

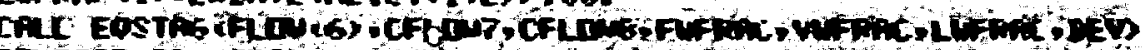

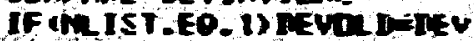

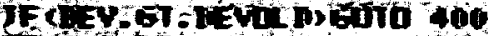

$C$

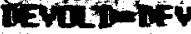
BD ten $I=1.2$

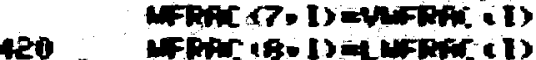

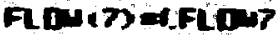

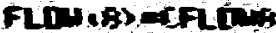

400 cominge

Do $450+1=1,7$

FHFREC (D)

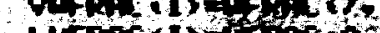

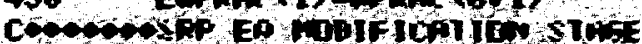

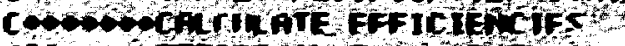

Cos

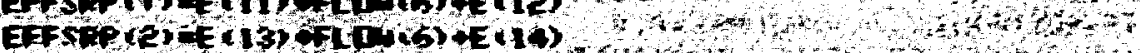

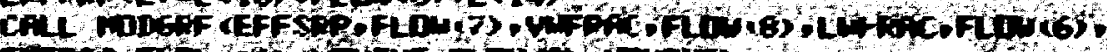

C F For FCu

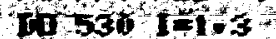

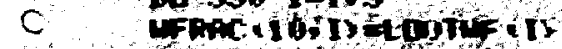

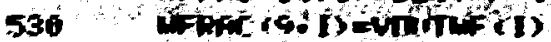

WITE (rB.20SU)

nd $6001=1010$

Frifutiol

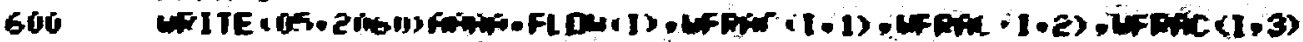

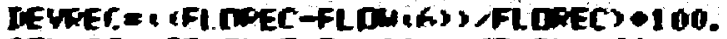

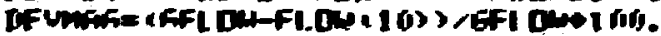

10 $6101=1.3$

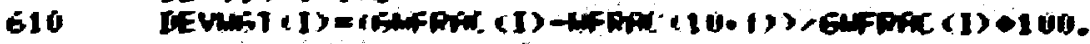
MFITE (C.2070)

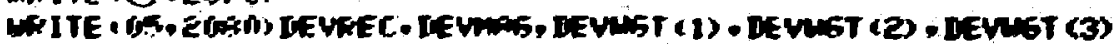
E010 20

COA-

2010 FBintiot (TFG, IS

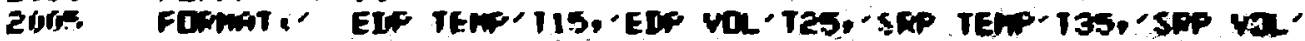

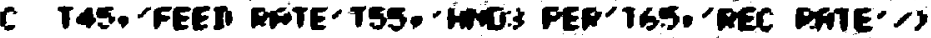

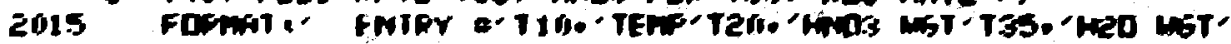

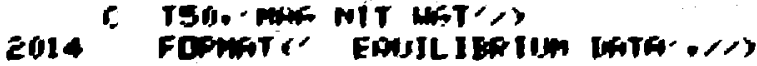

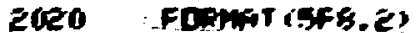

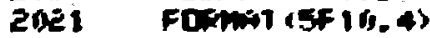

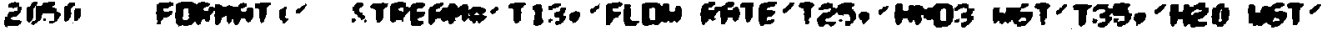

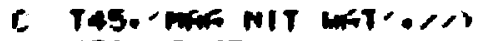

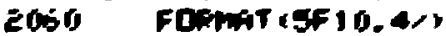

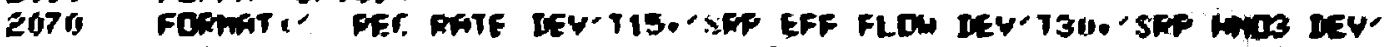

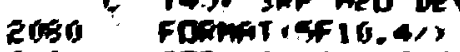

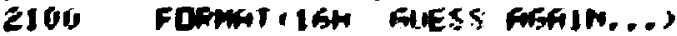

1 gord $210 \%$

ENI

$$
\geq 100
$$


WMWMWMMMUMMV

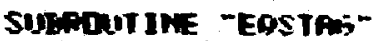

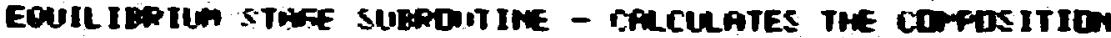

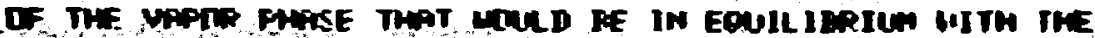

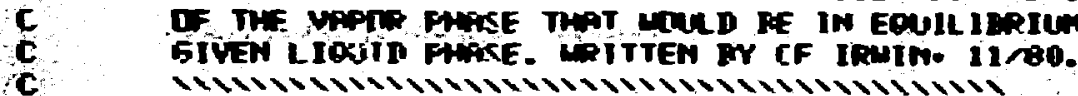

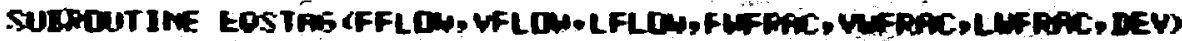

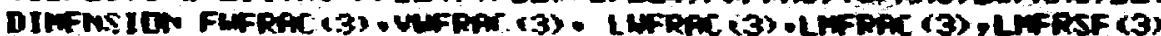

DIMENSION MTHFin (3)

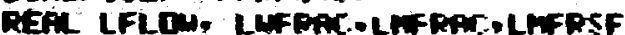

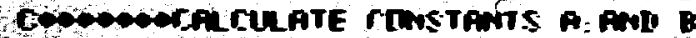

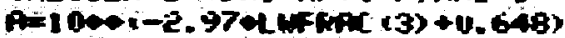

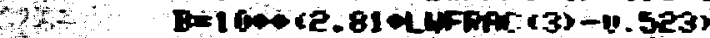

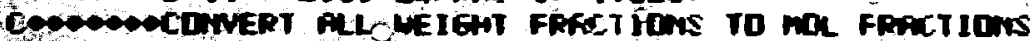

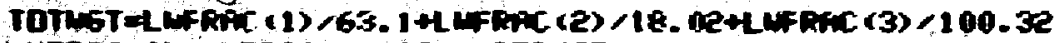

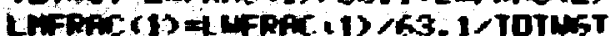

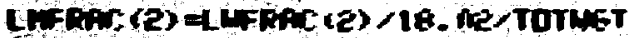

Q. 0 - of plat

DD $500-1=1 \cdot 2$

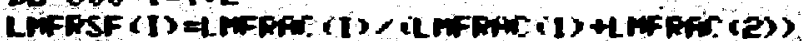

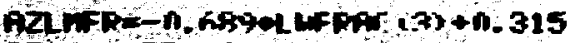

IF ERZLWFR.LT. O. O) RZL RF R=0.0

50

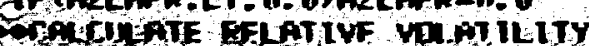

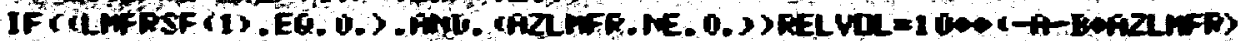

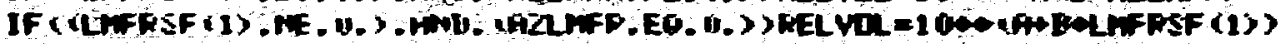

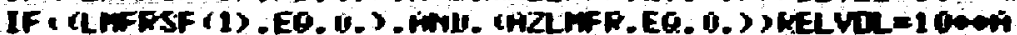

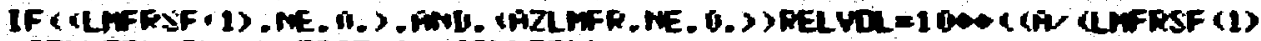

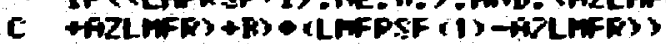

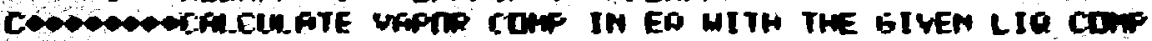

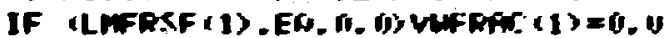

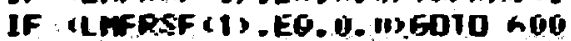

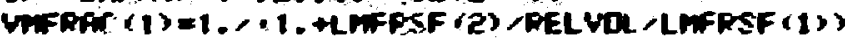

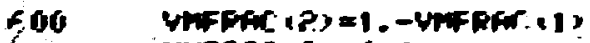

VMFFAC $(3)=0.0$

COO

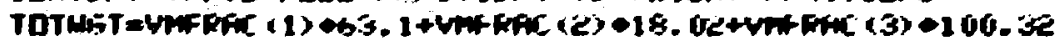

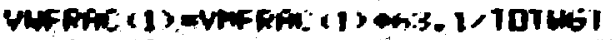

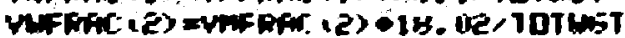

MUFPa, (3) $=0.0$

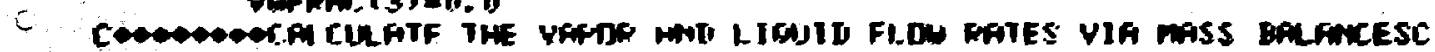

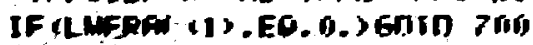

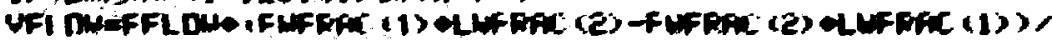

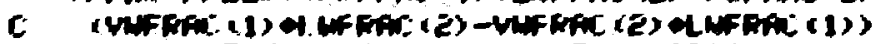

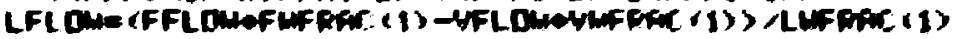
EOTO soî

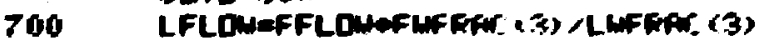

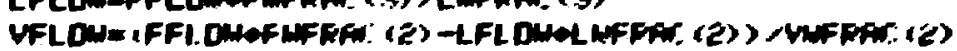

SoOs CONTICWE

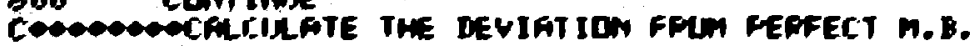

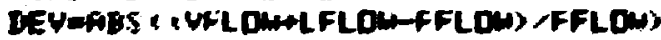

RETLON

ENID 
Function zeformaniditer

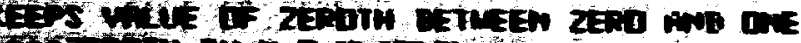

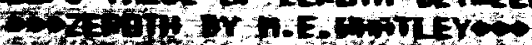

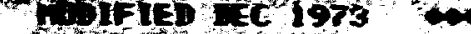

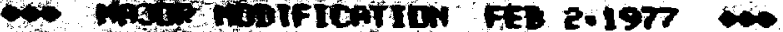

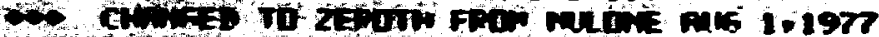

ptiknstion xtFias, rotis?

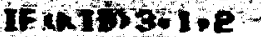

1 var (a)-Tin

If (o)t tret (a)-ref(3),-1.E-30) 30, 30,40

- IFTEY YPOSemis) 6.41.5

If Jotrioss 5012.4

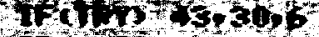

It $20,5,5,33$

IFTh-Th 45.33 .6

if (1)t-rite6) $46,30.5$

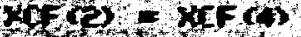

1408,3

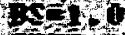

Sinis

$x, y \rightarrow(4)$

$x=5=12$

4s $30.05-1$

EगI0 7

6 Xpus-xcF (4)

YoTs-TPr

bS $185.85+1$.

7 DOSJ $=1.3$

YCF $(3)=4 C F()+1$.

8 XCF $(J)=X x+F(d+1)$

9 DBS= ABS (BS)

IF iXPDS OXME 6.6T, $n_{0}$, EOTD 11

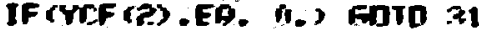

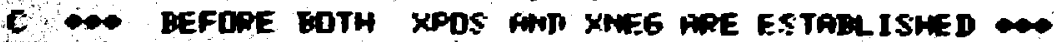

IF (XCF (3) - (1, - XIFF (3)) .LE. 0.) EOTD :3.3

$X C F(4)=X$ XF (3)-DRS - (X)F (3)-XCF (3)) AYCF (3) / (YCF (2)-YCF (3))

IDIE $J=1,10$

IF (xiCF (4) $\bullet 11,-x(F, 4)) 12,12,36$

$12 X C F(4)=(X C F(4)+X C F(3)) \geqslant e$.

BDTD $: x 3$

11 CIJT $=$ CUT +1 .

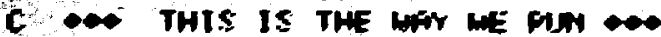

IF CGOTT.LT. 1.9 .DP. UBS.GT. 4.0) BS=U.

IF(DES - GT.3.5) Gnin zie

IF (DES . .T.E.3) GOTn Z7

C $\leftrightarrow$ SIMLE LIMEAF INTEPPDLATION

14 MES $=(\mathrm{BS}-.6)+(\mathrm{BBK}+.8)$

FAF = NBSEEXF (-rUT)

IF (NES-ES) RA-Zb-Z)

24 YFDS= YPOSWE.(4,1.-DBS) 
6010 is

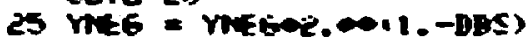

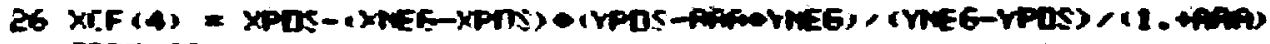
EDTd 29

C $\infty$ TRIEs a papabor. IC FIT

27 antin.

cresen.

$B B B=0$.

XY.F (A) $=X(F)(1)$

YCF (A) EWFF(1)

$\operatorname{YCF}(5)=\operatorname{VCF}(2)$

IDEeg $J=1,3$

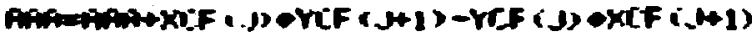

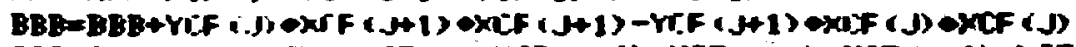

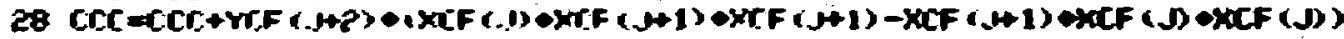
RAD= BBBQBRR-4.

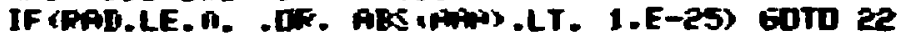

HaD $=0.50500 \mathrm{~T}$ (

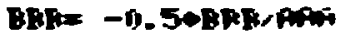

$X C F(4)=B B R+F A D$

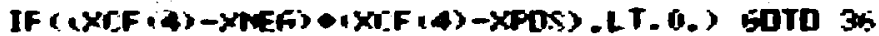

XCF $(4)=B B R-D A N$

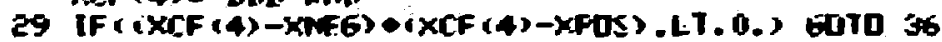

c. $\infty$ BISECTS INTEPYPL $\cdots$

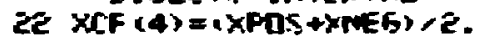

C THIS waY DUT

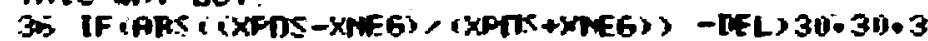

30 ID $=-1$

3 ZERDTHE XTF (4)

RETISTN

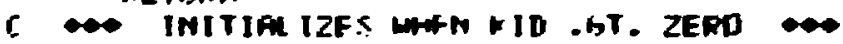

E XIF (4) $=$ TEY

CUT $=n$.

XPOS $=n$.

XWE $=0$.

YFDS $=0$.

YMES $=0$.

YCF (3) $=11$.

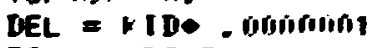

DEL = ARS IFL'

KID $=$ in

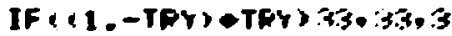

r. FIFST STEP

31 XCF (4) $=0.90 \times 1 F(3)$

$\mathrm{ES}=\mathrm{n}$.

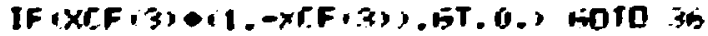

33 WITE IK. 133)

5010 30

1.33 FOFMAT ? VIOLATION OF ZEFOTH')

END 


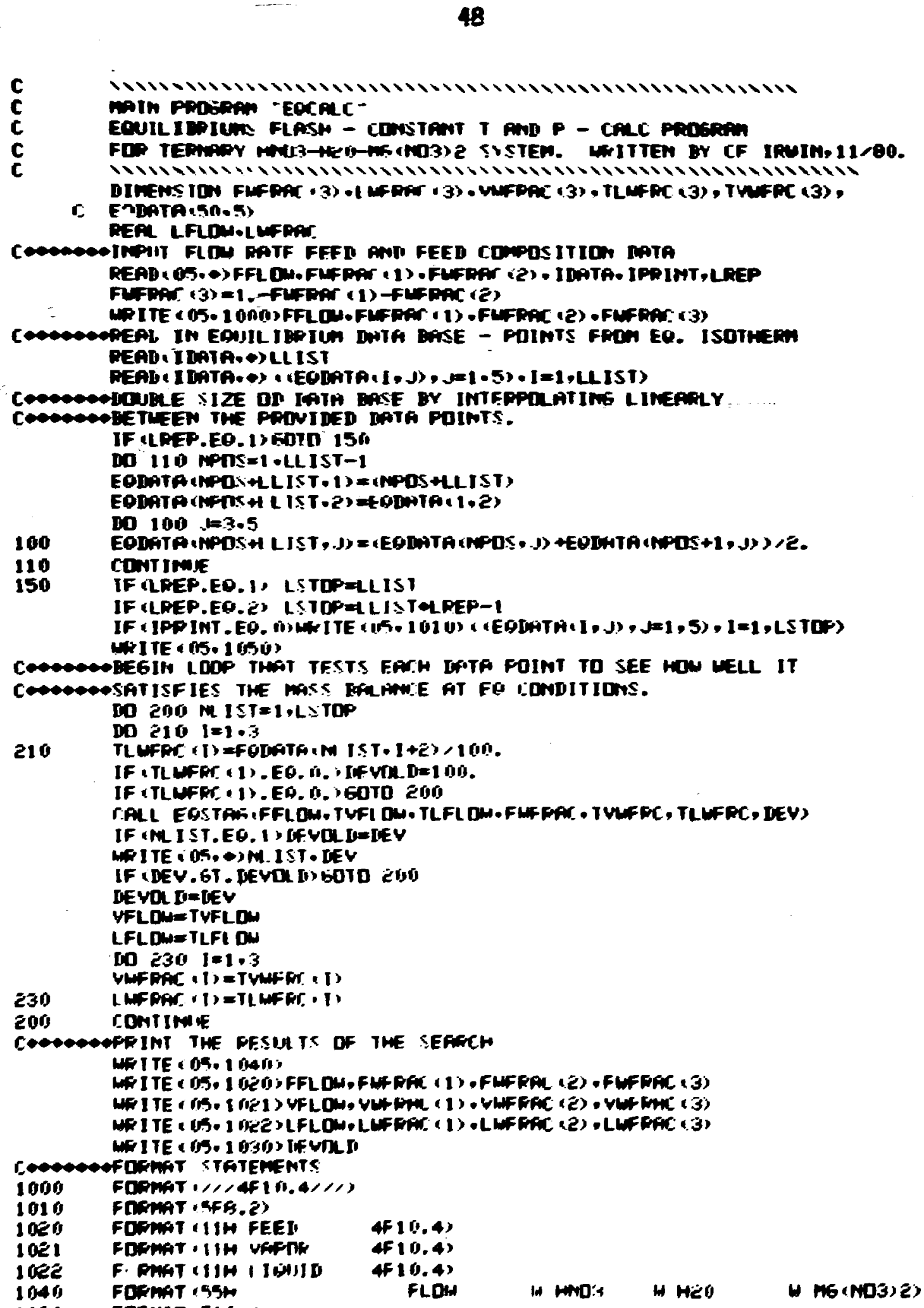




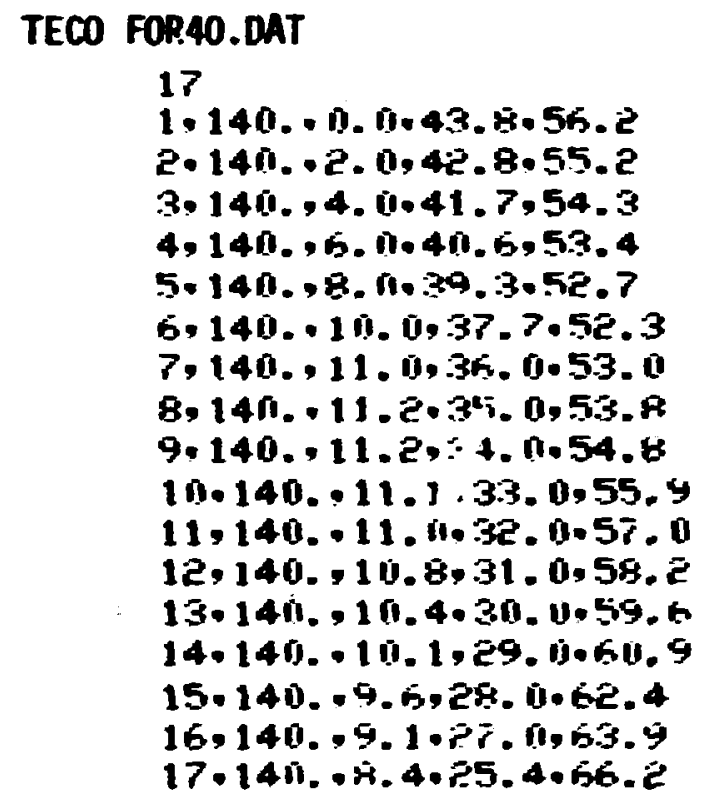

TECO FOR55,DAT

15

$1 \cdot 155 . \cdot 0.0 \cdot 38.2+61.8$ 2.155.1.10.37.2,61.8 3.155..2. 1..36.2.61.8 4.155.,3.11.35.11.62. v

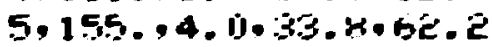
‥155. .4.2. . 32.8.63.1 $7.155 ., 4.4,31.6 .64 .0$ 8.155. .4.5,311.5065. 10 $9.155 .04 .5,29.5 \cdot 46.10$ $111.15 .5 ., 4.5 .28 .5 .67 .01$ $11 \cdot 155 . \cdot 4.5,27.5 \cdot 68.0$ $12,155 .+4.5,26.5 .69 .0$ $13 \cdot 155 .+4.5 \cdot 25.5 \cdot 70.0$

\section{TECO FOR60.DAT}

$1.165 .0 .0 .34 .8,65.2$ $2,165 ., 1,1,3: 3.5,0.5 .2$ 3.165.,2.10,32.8.6.5. $4.165 .93 .0 .31 .5 \cdot 65.5$ $5.165 .9 .3 .3 \cdot 30.7 .65 .11$ 6.165., $3.5,79.5 .67 .0$ 7.165., 3.6. 28.4068 .0 8, 165.-.7.7.27.3,69.11 4.165 .9 .7 .7 .26 .3 .711 .11 $10,165.9 .7,25.3 \cdot 71.0$ $11,165.93 .7 \cdot 24.3 \cdot 77.13$ 

$5 i$

$\begin{array}{ll}\text { P } & \text { pressure, cialitative } \\ \text { Q } & \text { heat input, qualitative } \\ \text { T } & \text { temperature, }{ }^{\circ} \mathrm{C} \\ \text { V } & \text { volume, ml } \\ \text { W } & \text { weight percent, wt } X \\ X & \text { liquid mole fraction } \\ Y & \text { vapor mole fraction } \\ Z & \text { combined feed mole fraction }\end{array}$

Greek Symbols

$\begin{array}{ll}n & \text { stage efficiency, } \% \\ \varepsilon & \text { error, } \% \\ \rho & \text { density, } g / \mathrm{cm}^{3}\end{array}$

Subscripts

$F, G, W, \rho, n$ refer to the quantities defined above d material balance direction EDP extractive distillation pot E EDP

feed acid feed i component $i$

L liquid

$\mathrm{Mg}\left(\mathrm{NO}_{3}\right)_{2}$ magnesium nitrate

o overall

S SP

SRP solvent recovery pot

vapor

* equilibrium; also a superscript

$1,2,3$ see tabulation mid-page 31 


\subsection{Literature References}

I. Counce, R.M., M.S. Groenier, and E.D. North, personal comunication, ORNL, November 1980.

C 2. Cigna, R., et al., "Effect of Alkali and Alkali-Earth Nitrates on the Liquid-Vapor Equilibrium of the Mater-Nitric Acid System," La Chimica e I'Industria, 46(1), 36 (1964).

3. Sloan, J.6., "The Extractive Distillation Process for Nitric Acid Concentration Using Magnesium Mitrate," Thermodynamic Behavior of Electrolytes in Mixed Solvents, pp. 128-142, American Chemical Society, Chicago, I11. (1975).

4. Scheerson, A.L., et al., "Liquid-Vapor Equilibria in the Systems Nitric Acid-Water-Magnesium Nitrate, Nitric Acid-Water-Calcium Nitrate, and Nitric Acid-Hater-Magnesi um Nitrate-Calcium Nitrate," Russian J. Phys. Chem., 39(6), 744 (1965).

5. Counce, R.M., personal commun ication, ORML, November 1, 1980.

6. Dean, J.A., ed., Lange's Handbook of Chemistry, 11 th ed., pp. $10,101,102$, McGraw-Hill, New York, 1973.

7. Rainey, R.H., "The Densities of Magnesium Nitrate Salts from Their Melting Temperatures to $240^{\circ} \mathrm{C}, "$ ORNL/CF-75-1-19, 1975. York, 1971 .

8. King, C.J., Separation Processes, pp. 601-605, McGraw-Hill, New

9. Box, G.E.P., W.G. Hunter, and J.S. Hunter, Statistics for Experimentors, Pp. 208-243, Wiley, New York, 1978.

10. Shreve, R.N., Chemical Process Industries, 3rd ed., Pp. 318-320, McGraw-Hill, New York, 1967. 